\title{
The Chloroplast Gene ycf9 Encodes a Photosystem II (PSII) Core Subunit, PsbZ, That Participates in PSII Supramolecular Architecture
}

\author{
Magdalena Swiatek, , ${ }^{\mathrm{a}, 1}$ Richard Kuras,, ${ }^{\mathrm{b}, 1}$ Anna Sokolenko, ${ }^{\mathrm{a}, 1}$ David Higgs,, ${ }^{\mathrm{c}, 2}$ Jacqueline Olive, ${ }^{\mathrm{d}}$ \\ Gianfelice Cinque, ${ }^{e}$ Bernd Müller, ${ }^{a}$ Lutz A. Eichacker, ${ }^{a}$ David B. Stern, ${ }^{\mathrm{c}}$ Roberto Bassi,e \\ Reinhold G. Herrmann, ${ }^{a}$ and Francis-André Wollman ${ }^{b, 3}$ \\ a Botanisches Institut der Ludwig-Maximilians-Universität, Menzingerstrasse 67, D-80638 Munich, Germany \\ b Unité Propre de Recherche-Centre National de la Recherche Scientifique 1261, Institut de Biologie Physico-Chimique, 13 \\ rue Pierre et Marie Curie, 75005 Paris, France \\ ${ }^{c}$ Boyce Thompson Institute for Plant Research, Cornell University, Ithaca, New York 14853 \\ dInstitut Jacques Monod, Université Paris 7, 2 Place Jussieu, 75251 Paris, France \\ e Dipartimento Scientifico e Tecnologico, Università di Verona, Strada Le Grazie, 37134 Verona, Italy
}

We have characterized the biochemical nature and the function of PsbZ, the protein product of a ubiquitous open reading frame, which is known as ycf9 in Chlamydomonas and ORF 62 in tobacco, that is present in chloroplast and cyanobacterial genomes. After raising specific antibodies to PsbZ from Chlamydomonas and tobacco, we demonstrated that it is a bona fide photosystem II (PSII) subunit. PsbZ copurifies with PSII cores in Chlamydomonas as well as in tobacco. Accordingly, PSII mutants from Chlamydomonas and tobacco are deficient in PsbZ. Using psbZ-targeted gene inactivation in tobacco and Chlamydomonas, we show that this protein controls the interaction of PSII cores with the light-harvesting antenna; in particular, PSII-LHCII supercomplexes no longer could be isolated from PsbZ-deficient tobacco plants. The content of the minor chlorophyll binding protein CP26, and to a lesser extent that of CP29, also was altered substantially under most growth conditions in the tobacco mutant and in Chlamydomonas mutant cells grown under photoautotrophic conditions. These PsbZ-dependent changes in the supramolecular organization of the PSII cores with their peripheral antennas cause two distinct phenotypes in tobacco and are accompanied by considerable modifications in (1) the pattern of protein phosphorylation within PSII units, (2) the deepoxidation of xanthophylls, and (3) the kinetics and amplitude of nonphotochemical quenching. The role of PsbZ in excitation energy dissipation within PSII is discussed in light of its proximity to CP43, in agreement with the most recent structural data on PSII.

\section{INTRODUCTION}

With the completion of an ever-increasing number of chloroplast genome sequences (Quigley and Weil, 1985; Bookjans et al., 1986; Ohyama et al., 1986; Shinozaki et al., 1986; Hiratsuka et al., 1989; Evrard et al., 1990; Hallick et al., 1993; Wakasugi et al., 1994, 1997; Kowallik et al., 1995; Maier et al., 1995; Reith and Munholland, 1995; Douglas and Penny, 1999; Sato et al., 1999; Turmel et al., 1999; Hupfer et al., 2000; Lemieux

\footnotetext{
1 These authors contributed equally to this work.

${ }^{2}$ Current address: University of Wisconsin-Parkside, Department of Biological Sciences, Kenosha, WI 53141.

${ }^{3}$ To whom correspondence should be addressed. E-mail wollman @ibpc.fr; fax 33-1-58-41-50-22.
}

et al., 2000), the functions of most of the major open reading frames of chloroplast DNA have now been studied. The ability to perform reverse genetics with tobacco and Chlamydomonas chloroplasts has contributed greatly to this process. However, this strategy, which consists mainly of the phenotypic characterization of mutants inactivated for the gene under study, can be unsuccessful in two cases: (1) when the gene product is required for cell viability, in which case homoplasmic transformation cannot be obtained, and (2) when homoplasmic transformants do not display any clear-cut mutant phenotype under laboratory conditions. In both cases, this may preclude a reliable functional characterization of the gene and its product.

ycf9, which is predicted to encode a $6.5-\mathrm{kD}$ protein with two putative membrane-spanning segments, is an interesting case because attempts to inactivate the gene have yielded widely different results ranging from potential lethality to 
neutrality. Higgs et al. (1998) observed that Chlamydomonas strains inactivated for ycf9 displayed a wild-type phenotype when grown under heterotrophic conditions (i.e., on medium containing acetate as a carbon source). In another study (Mäenpää et al., 2000), experiments based on ycf9 gene inactivation in tobacco led to the conclusion that it was an essential gene because no homoplasmic transformants could be recovered. These authors suggested that the ycf 9 product was localized in the chloroplast stromal membranes and likely was associated with photosystem I (PSI). In yet another study, also based on chloroplast gene inactivation in tobacco (Ruf et al., 2000), homoplasmic transformants were recovered successfully, but the ycf9 product was presented as the first member of a new family of small antenna proteins.

The ycf9 gene is ubiquitous among organisms that perform oxygenic photosynthesis, both prokaryotes (cyanobacteria) and eukaryotes (Cryptophyta, Euglenoids, Glaucocystophyceae, Rhodophyta, Stramenopiles, and Viridiplantae). In addition, it is present in all chloroplast genomes analyzed to date, whereas a number of the small chloroplast open reading frames identified in one photosynthetic eukaryote are often found in the nucleus of another organism. We combined chloroplast gene inactivation in Chlamydomonas and tobacco to understand the function of the ubiquitous ycf 9 product. We show that the ycf9 product is a genuine subunit of photosystem II (PSII) cores, which we named PsbZ. We provide evidence for its role in the interaction of PSII cores with the light-harvesting antenna, and we show that its absence in tobacco can lead to severe growth defects and/or increased light sensitivity.

\section{RESULTS}

\section{Comparison of Ycf9 Sequences}

Figure 1 shows that ycf9 genes from a variety of photosynthetic organisms encode a well-conserved protein. The Chlamydomonas sequence shows $\sim 60 \%$ identity with the sequences of vascular plants, including tobacco, whose sequence is paired with that of Chlamydomonas in Figure 1. Sequence similarity exists throughout, with the dominant feature being two hydrophobic stretches long enough to give rise to transmembrane (TM) $\alpha$ helices (underlined at the bottom of Figure 1). These putative TM helices are separated by a loop of $\sim 15$ amino acids that are predicted to be lumenal, provided the $\mathrm{N}$ terminus of the protein is retained on the stromal side of the membranes. Interestingly, we noted the presence of a putative processing site for the lumenal peptidase, VFA, in the cases of Chlamydomonas and vascular plants (boxed in Figure 1) located at the end of the first putative TM helix. Processing of the $6.5-\mathrm{kD}$ polypeptide at this site would yield a protein 34 residues in length (i.e., $\sim 3.5 \mathrm{kD}$ ).

\section{Construction of Strains Inactivated for ycf9}

We took a reverse genetics approach to understand the function of ycf 9 by constructing strains in which the ycf 9 gene was replaced by a selectable marker cassette. In Chlamydomonas, ycf 9 is found immediately upstream of a

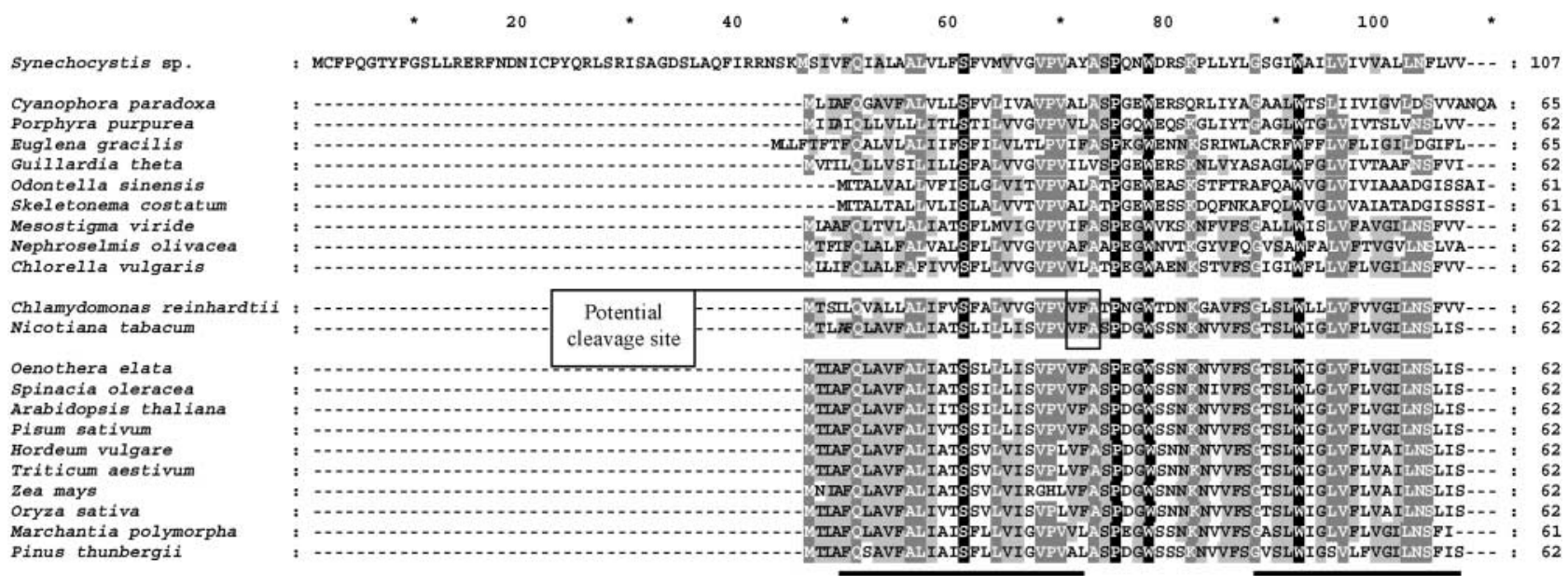

Figure 1. Multiple Sequence Alignment of Predicted ycf9 Gene Products.

Shading is according to the percentage of identity among sequences: $100 \%$ (black), $80 \%$ (dark gray), and $60 \%$ (light gray). Underlining at the bottom indicates the extent of residues predicted to form transmembrane helices. A potential cleavage site for the lumenal peptidase is boxed in the Chlamydomonas and tobacco sequences at center. Accession numbers are given in Methods. Numbers at top are the numbering of the predicted ycf9 gene product in Synechocystis. Numbers at right indicate the length (in amino acids) of the predicted ycf9 gene product for each organism. 
PSIl gene, psbM (Higgs et al., 1998). The two genes are cotranscribed, giving rise to a $2.7-\mathrm{kb}$ dicistronic mRNA. To address the function of the ycf 9 product, we used chloroplast transformation to replace the ycf 9 open reading frame with an aadA cassette in the antisense orientation (Figure $2 \mathrm{~A})$; aadA confers resistance to spectinomycin and streptomycin. After two rounds of subcloning on Tris-acetatephosphate (TAP) medium - which supports heterotrophic growth-supplemented with spectinomycin, two independent transformants were further characterized by DNA filter hybridization and confirmed to be homoplasmic for the ycf9 replacement (data not shown). The $\Delta y c f 9$ strains did not accumulate the 2.7-kb dicistronic transcript, as determined by hybridization with a $p s b M$ probe, but they did accumulate wild-type levels of the $0.7-\mathrm{kb}$ monocistronic $p s b M$ transcript (Figure 2B). Because it has previously been reported that monocistronic transcripts-but not the downstream cistron of dicistronic transcripts-are competent for translation in Chlamydomonas (Sturm et al., 1994; Majeran et al., 2001), it is most likely that we did not compromise the expression of psbM in $\Delta y c f 9$ strains.

In tobacco, ycf9 is located in a small gene cluster flanked by the PSIl genes $p s b D$ and $p s b C$ upstream and trnG downstream. A terminatorless aadA cassette was inserted into the Munl site of ycf9 on the plastid chromosome (Figure $3 A$ ). Insertion of the cassette was designed to interrupt ycf9 at the sixth codon without notably disturbing the expression of the preceding genes ( $p s b C$ and $p s b D$ ) or of the downstream $\operatorname{trn} G$ gene. However, the insertion caused a frameshift in ycf9, preventing translational reinitiation of transcripts containing the C-terminal gene segment. Correct insertion of the aadA cassette and homoplasmic status were checked by sequence, polymerase chain reaction (PCR), and DNA filter hybridization analyses (data not shown; for methods, see De Santis-Maciossek et al., 1999). RNA filter hybridization analysis performed with all relevant probes (Figure 3B) was consistent with the desired genome structure. We observed six different transcripts emanating from the $p s b D-p s b C$-ycf 9 cluster, whereas trnG appeared to be transcribed independently, as reported previously (Yao et al., 1989). Most of the transcripts identified with the $p s b C, y c f 9$, and aadA probes in $\Delta y c f 9$ plants were larger by $\sim 0.9 \mathrm{~kb}$, the length of the inserted aad $A$ cassette. The expression of the downstream trnG gene was not modified detectably by this insertion (Figure $3 \mathrm{~B}$ ). Thus, the complex pattern caused by post-transcriptional RNA processing was modified only in those RNA species that included the aadA insertion, and no wild-type signals could be detected, even in overloaded gels (data not shown).

\section{Growth Phenotypes of Chloroplast Transformants Inactivated for ycf9}

The mutant tobacco lines were able to survive in soil and produced fertile seed. This confirmed that their phenotype
A

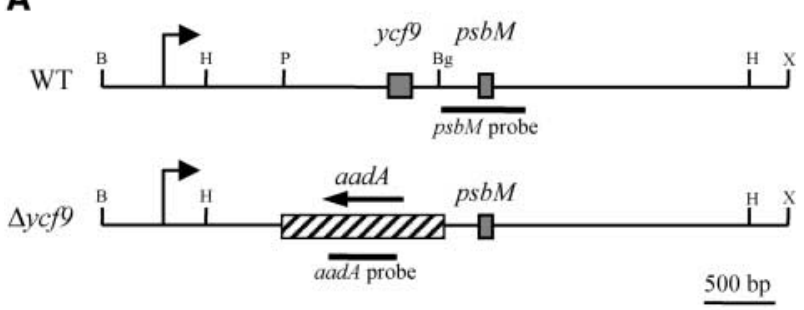

Chlamydomonas

B

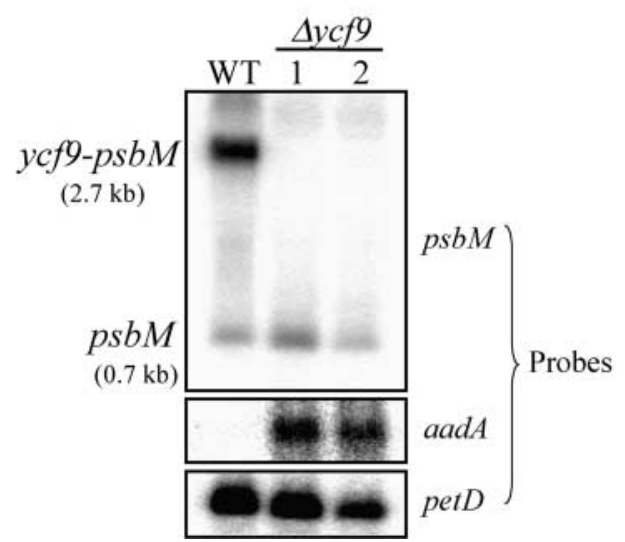

Figure 2. Detection of the Transcripts of the ycf9-psbM Region in Wild-Type and $\Delta y c f 9$ Chlamydomonas Strains.

(A) Maps of the ycf9-psbM region in wild-type and $\Delta y c f 9$ Chlamydomonas chloroplasts. The positions of the probes used in RNA filter hybridizations are indicated below each map. The bent arrow indicates the position of the $y c f 9$ promoter (D. Higgs and D.B. Stern, unpublished results); an additional promoter may exist for $p s b M$, but it has not been mapped. Restriction sites shown are $\mathrm{B}, \mathrm{BamH} ; \mathrm{H}$, HindIII; P, Pstl; Bg, Bglll; and X, Xhol.

(B) RNA accumulation in wild-type cells and two $\Delta y c f 9$ transformants. Probes are shown at the right, with pet $D$ as a loading control. WT, wild type.

was photoautotrophic, as was the case for Chlamydomonas (see below). However, the tobacco lines showed two clear non-wild-type phenotypes, depending on the growth conditions used. Under standard heterotrophic conditions (at $25^{\circ} \mathrm{C}$ under $100 \mu \mathrm{E} \cdot \mathrm{m}^{-2} \cdot \mathrm{sec}^{-1}$, with growth medium supplemented with sucrose), $\Delta y c f 9$ plants developed pale green leaves of the reticulate type (Figures $4 \mathrm{~A}$ and $4 \mathrm{~B}$ ), corresponding to a 2.5-fold decrease in the chlorophyll content of the mutant plant compared with that of the wild-type plant. This effect was less apparent when plants where grown in soil in the greenhouse. However, at variance with Ruf et al. (2000), we did not observe differences in growth rates at 
A
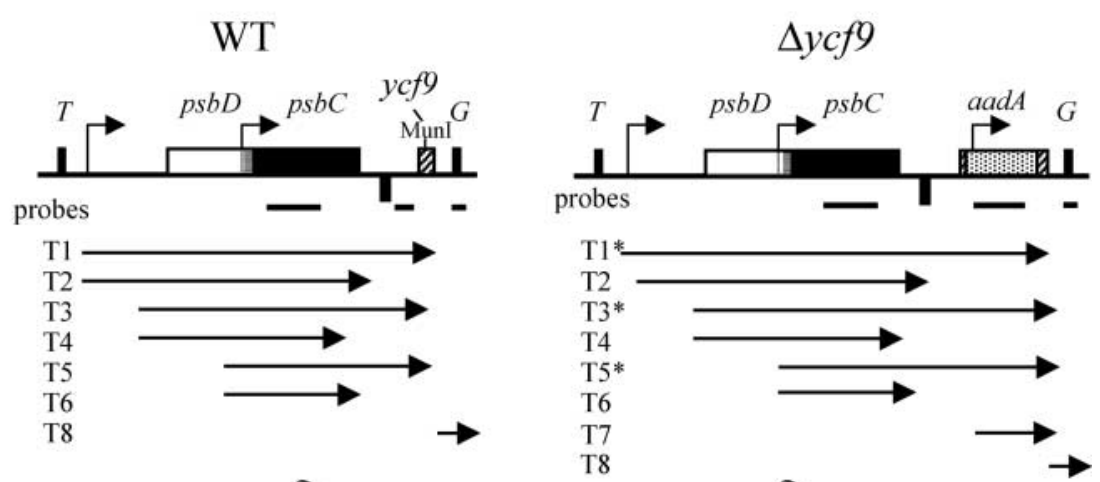

B

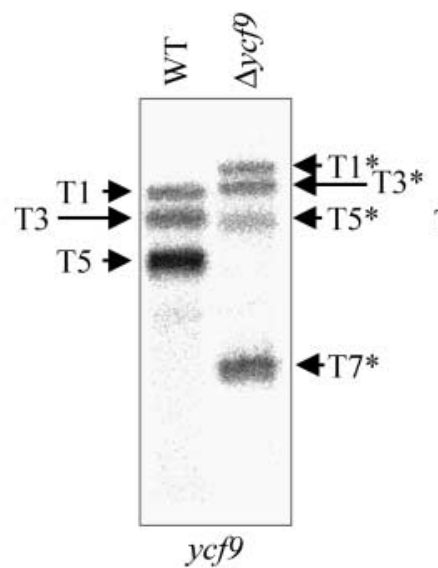

T8
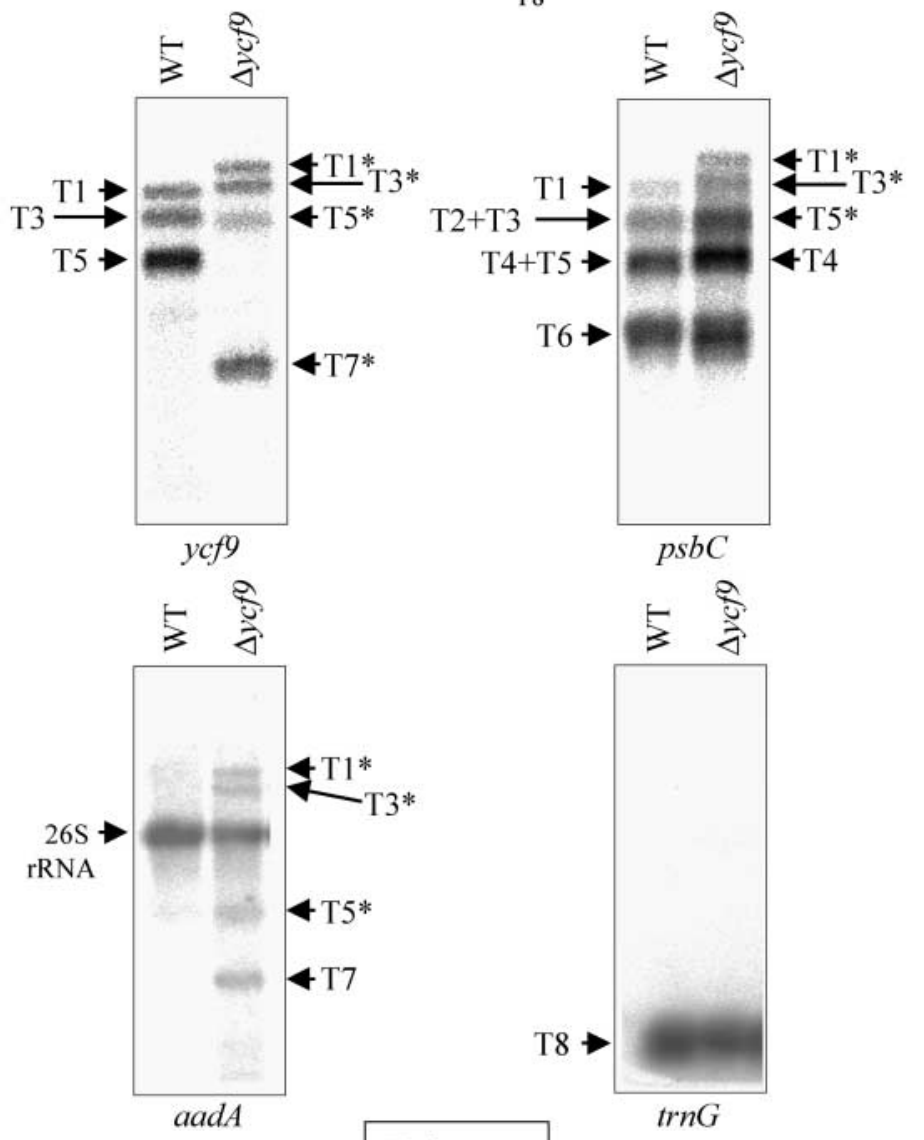

Tobacco

Figure 3. Overview of the Gene Expression of the ycf9 Region in Wild-Type and Mutant Tobacco Plants.

(A) Maps of the $p s b D / p s b C$-ycf9 gene cluster in the wild-type and $\Delta y c f 9$ tobacco chloroplasts. $T, \operatorname{trn} T$; $G$, trnG. The gene on the opposite strand, between $p s b C$ and $y c f 9$, is trnS. Known promoters are shown as bent arrows. The Munl site used for insertion of the aadA cassette is indicated on the wild-type restriction map. Below each map, horizontal lines indicate the positions of probes used for RNA filter hybridization analysis. The deduced or known extents of transcripts are shown as arrows. The complex pattern in the wild-type chloroplasts is according to Yao et al. (1989), whereas the transcripts in the $\Delta y c f 9$ transformant were deduced by extrapolation from the wild-type RNAs. Transcript sizes in the wild type are as follows: T1, $4.4 \mathrm{~kb}$; T2, $3.6 \mathrm{~kb}$; T3, $3.6 \mathrm{~kb}$; T4, $2.6 \mathrm{~kb}$; T5, $2.6 \mathrm{~kb} ; \mathrm{T} 6,1.7 \mathrm{~kb}$; and T8, $0.71 \mathrm{~kb}$. In the transformant, the sizes of transcripts modified by the aadA insertion (indicated by asterisks) are as follows: $\mathrm{T1}^{\star}, 5.3 \mathrm{~kb}$; T3*, $4.5 \mathrm{~kb}$; and T5*, $3.5 \mathrm{~kb}$. The size of T7 is $1.3 \mathrm{~kb}$. (B) RNA accumulation patterns analyzed using the probes indicated below each panel.

WT, wild type. 
$25^{\circ} \mathrm{C}$. When transferred to a lower temperature $\left(20^{\circ} \mathrm{C}\right), \Delta y c f 9$ plants displayed a drastic decrease in growth rate at low light intensities (10 $\mu \mathrm{E} \cdot \mathrm{m}^{-2} \cdot \mathrm{sec}^{-1}$; Figure $\left.4 \mathrm{D}\right)$. This dwarf phenotype was progressively lost with increasing light intensities (up to $100 \mu \mathrm{E} \cdot \mathrm{m}^{-2} \cdot \mathrm{sec}^{-1}$; Figure $4 \mathrm{C}$ ) .

At $25^{\circ} \mathrm{C}$, Chlamydomonas $\Delta y c f 9$ grew photoautotrophically at the same rate as did the wild type (i.e., Chlamydomonas cells containing only the aadA selectable marker cassette) under a broad range of light intensities (from 20 to $\left.200 \mu \mathrm{E} \cdot \mathrm{m}^{-2} \cdot \mathrm{sec}^{-1}\right)$. Decreasing the temperature to $17^{\circ} \mathrm{C}$ caused a drastic decrease in photoautotrophic growth rates in both wild-type and $\Delta y c f 9$ cells (their generation times increased to $>24 \mathrm{hr}$ ) but failed to cause a significant difference in their relative growth rates. In all instances, the wild type and the mutant algae retained a similar chlorophyll content with a chlorophyll $a / b$ ratio of 2.2.

\section{Changes in Polypeptide Content in Thylakoid Membranes from $\Delta y c f 9$ Mutants}

Because ycf9 is predicted to encode a membrane protein, we analyzed thylakoid membrane proteins, comparing wildtype and $\Delta y c f 9$ material. Figure 5 shows a comparison of thylakoid membrane proteins from heterotrophically grown wild-type and $\Delta y c f 9$ Chlamydomonas strains and tobacco plants. After denaturing SDS-PAGE, silver staining of the $\Delta y c f 9$ proteins revealed a clear polypeptide deficiency in the lowmolecular-weight region of the gels. We attributed the identity of the deficient low-molecular-weight polypeptide unambiguously to the $y c f 9$ product by using polyclonal antibodies (see below) raised against a peptide sequence specific either to the Chlamydomonas or the tobacco polypeptide (see Figures 7A and 7B).
We noted that the ycf9 product from Chlamydomonas behaved as an $\sim 6-\mathrm{kD}$ band in the SDS-tricine-PAGE $(16.5 \%$ acrylamide) system (Figure $5 \mathrm{~A}$ ), whereas it migrated close to the front of the gel, that is, as an $\sim 3-\mathrm{kD}$ band, in a ureaSDS-Tris-glycine-PAGE system (data not shown). Thus, it remained ambiguous whether the protein was processed in vivo, as suggested by its sequence (Figure 1). In comparing the tobacco protein samples, an additional quantitative difference was seen in a region of higher molecular weight, $\sim 26$ $\mathrm{kD}$ (Figure 5B, top arrow). As discussed below, this corresponds to one of the minor chlorophyll antenna proteins.

\section{Evidence That the ycf9 Product, PsbZ, Is a Genuine Subunit of PSII Cores}

To determine the precise localization of the ycf 9 product, hereafter referred to as PsbZ, we further fractionated thylakoid membrane polypeptides by sedimentation through sucrose gradients after solubilization with a combination of Triton X-100 and digitonin for Chlamydomonas (Figure 6) and $\beta$-dodecylmaltoside for tobacco (see Figure 8). For Chlamydomonas, immunoblotting using pooled gradient fractions showed that PsbZ comigrated precisely with the PSII core subunits, as represented by CP43 in Figure 6. The apparent association of PsbZ with PSIl cores was further substantiated by an analysis of PsbZ accumulation in a variety of Chlamydomonas mutants (Figure 7A). Although PsbZ was present in mutants lacking PSI (F15), ATP synthase (Fud50), chlorophyll $a / b$ antenna proteins (BF4), or the cytochrome $b_{6} / f$ complex (Fud6), it was absent in mutants lacking in PSII cores, as exemplified by Fud7, whose primary defect is a large deletion within the $p s b A$ gene encoding the D1 reaction center protein (Erickson et al., 1989), and by

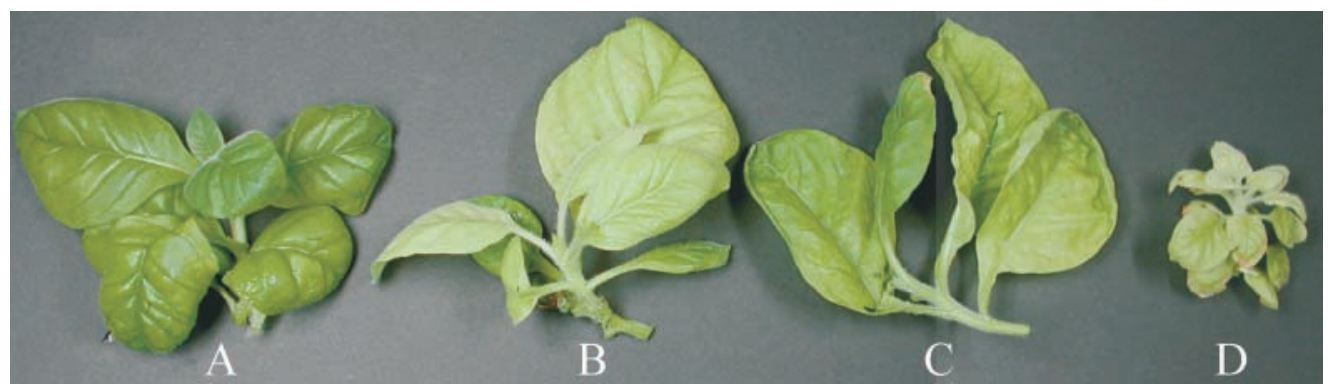

Figure 4. Phenotypes of Wild-Type and $\Delta y c f 9$ Tobacco Plants.

(A) Wild type plants grown under high light at $25^{\circ} \mathrm{C}$.

(B) $\Delta y c f 9$ grown under high light at $25^{\circ} \mathrm{C}$.

(C) $\Delta y c f 9$ grown under high light at $20^{\circ} \mathrm{C}$.

(D) $\Delta y c f 9$ grown under dim light at $20^{\circ} \mathrm{C}$.

Plants were grown on Murashige and Skoog (1962) medium containing $20 \mathrm{~g} / \mathrm{L}$ sucrose. Wild-type plants grown at $20^{\circ} \mathrm{C}$ under $10 \mu \mathrm{E} \cdot \mathrm{m}^{-2} \cdot \mathrm{sec}^{-1}$ had the same phenotype as shown in (A). Dim light (DL), $10 \mu \mathrm{E} \cdot \mathrm{m}^{-2} \cdot \mathrm{sec}^{-1}$; high light (HL), $100 \mu \mathrm{E} \cdot \mathrm{m}^{-2} \cdot \mathrm{sec}^{-1}$. 
A

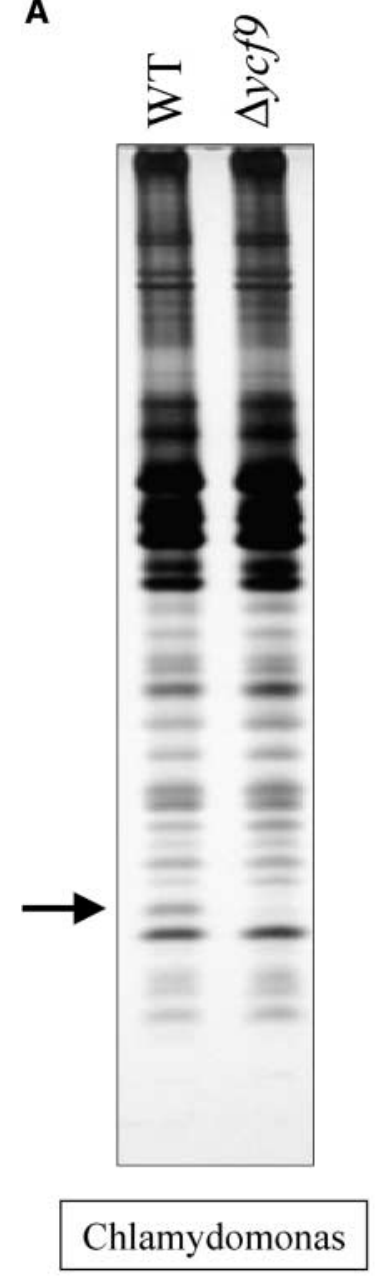

B

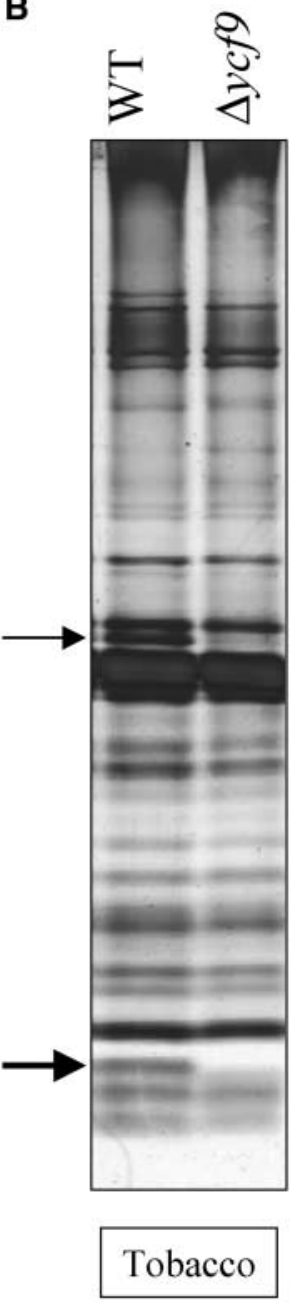

Figure 5. Fractionation of Thylakoid Membrane Polypeptides.

(A) From Chlamydomonas grown in minimal medium at $25^{\circ} \mathrm{C}$ under $10 \mu \mathrm{E} \cdot \mathrm{m}^{-2} \cdot \mathrm{sec}^{-1}$. The gel system was SDS-tricine-16.5\% polyacrylamide. (B) From tobacco plants grown at $25^{\circ} \mathrm{C}$ under $100 \mu \mathrm{E} \cdot \mathrm{m}^{-2} \cdot \mathrm{sec}^{-1}$. The gel system was SDS-tricine- $13.5 \%$ polyacrylamide.

Proteins were revealed with silver staining. Arrows indicate the positions of polypeptide deficiencies in the transformants. The boldface arrows indicate Ycf9 bands, whereas the lighter arrow in (B) indicates CP26. WT, wild type.

F34, whose primary defect is a block in translation of apoCP43 (Rochaix et al., 1989; Zerges and Rochaix, 1994). It also was absent, as expected, in the knockout mutant described in Figure 2 ( $\Delta y c f 9)$ and in RevFud6, a strain in which the ycf9 gene has been inactivated due to a large inversion in the chloroplast genome (Higgs et al., 1998). On the other hand, we note that PsbZ accumulated normally in BF25, a mutant that accumulates PSII cores but lacks the oxygenevolving enhancer subunits. When the tobacco thylakoid proteins were solubilized with $\beta$-dodecylmaltoside and separated by sucrose gradient centrifugation (Figure 8 ), the sil- ver-stained band that we attributed to PsbZ was found in the PSII core fractions from the wild-type plants, whereas it was absent from the PSII core fractions of the $\Delta y c f 9$ plants (data not shown). Moreover, thylakoid membranes of a PSII tobacco mutant, encompassing an insertion of the aadA cassette after the second codon of the $p s b F$ gene (R. Regel and R.G. Herrmann, unpublished data), also failed to accumulate PsbZ, as shown by immunoblot analyses (Figure 7B). Thus, we conclude that the ycf9 gene product behaves as a genuine PSII core subunit. In both tobacco and Chlamydomonas, it remains associated with the PSII core complexes after 
detergent solubilization of thylakoid membranes and is absent in thylakoid membranes of mutants unable to accumulate the PSII core subunits.

\section{PsbZ-Dependent Formation of PSII Supercomplexes}

PSIl subunits from tobacco thylakoids are found at several distinct positions after membrane solubilization with $\beta$-dodecylmaltoside and sucrose gradient sedimentation (Müller and Eichacker, 1999). Gradients from $\Delta y c f 9$ and wild-type tobacco are compared in Figure 8A. The heaviest PSII-containing fractions correspond to PSII-light-harvesting complex II (LHCII) supercomplexes, with increasingly less quickly sedimenting complexes corresponding to PSIl core dimers and PSII core monomers. Figure $8 \mathrm{~A}$ shows clearly that in $\Delta y c f 9$ plants, there was little or no material at the position of the PSII-LHCII supercomplexes. Fractions through the entire gradient were separated by SDS-PAGE, transferred to membranes, and analyzed by immunoblotting, as shown in Figure 8B. The PSII reaction center protein D1 was found in the three PSIl-containing fractions from wild-type plants but failed to accumulate at the position of PSII supercomplexes in $\Delta y c f 9$ plants (cf. fractions 29 and 33). A similar phenomenon was observed for LHCIl, the major peripheral antenna protein; it was depleted selectively in the expected position of PSIl supercomplexes in the mutant plants. In contrast, the most quickly sedimenting green band, consisting of PSI supercomplexes, was present in wild-type and $\Delta y c f 9$ material, as demonstrated by immunodetection of the PSI reaction center (fractions 34 and 35). The absence of PSII supercomplexes in $\Delta y c f 9$ correlates with an increased amount of the slower sedimenting PSIl dimers (fractions 25 to 28).

Extensive studies of freeze-fractured thylakoid membranes have demonstrated that PSII proteins can be visualized on the exoplasmic faces (EF) as particles whose sizes depend on their biochemical composition (reviewed in Olive and Wollman, 1998). PSII cores give rise to particles 8 to $11 \mathrm{~nm}$ in diameter, whereas PSIl complexes that contain various amounts of peripheral antenna proteins give rise to two size classes of larger particles, 11 to $13 \mathrm{~nm}$ and 15 to $18 \mathrm{~nm}$ in diameter. Therefore, we measured EF particle sizes in freeze-fractured thylakoids from the wild type and $\Delta y c f 9$ mutants from tobacco and Chlamydomonas grown under standard heterotrophic conditions $\left(25^{\circ} \mathrm{C}, 100 \mu \mathrm{E} \cdot \mathrm{m}^{-2}\right.$. $\left.\mathrm{sec}^{-1}\right)$. For the analysis of tobacco, we used green leaves from the mutant to avoid secondary effects resulting from bleaching.

Our analysis revealed no differences in the densities of EF particles between mutant and wild-type membranes, in agreement with their similar PSII contents (data not shown). However, the histograms summarizing EF particle sizes showed significant differences. In wild-type tobacco (Figure 9A), most of the particles had sizes from 10 to $21 \mathrm{~nm}$, with two major size classes peaking at $14 \mathrm{~nm}$ and 16 to $17 \mathrm{~nm}$. This result is consistent with previous reports (Armond et al.,
1977) and reflects differences in the amount of antenna proteins that remains associated with the 8- to 11-nm PSII cores upon freeze fracture. The $\Delta y c f 9$ mutant displayed a shift to particles of smaller size, with a marked increase in the populations of $10-\mathrm{nm}$ particles, corresponding to PSII cores, and of 12- to 14-nm particles, which appear to accumulate at the expense of the population $>15 \mathrm{~nm}$ in diameter. The same three classes of EF particles were found in the thylakoids of wild-type Chlamydomonas (Figure 9B), albeit in different proportions than in tobacco. The major class peaked in the 12- to 14-nm region, with additional populations in the 10- and 16-nm regions. Chlamydomonas $\Delta y c f 9$, like the tobacco mutant, displayed smaller particles than did the wild-type control; the histogram peaked at $9 \mathrm{~nm}$, and particles $>12 \mathrm{~nm}$ accounted for only $20 \%$ of the total population. Thus, the electron microscopy data confirm the selective loss of PSIl supercomplexes.

\section{PsbZ-Dependent Accumulation of Minor Antenna Protein Complexes}

Neither Chlamydomonas nor tobacco $\Delta y c f 9$ mutants displayed evidence of a loss of the major light-harvesting

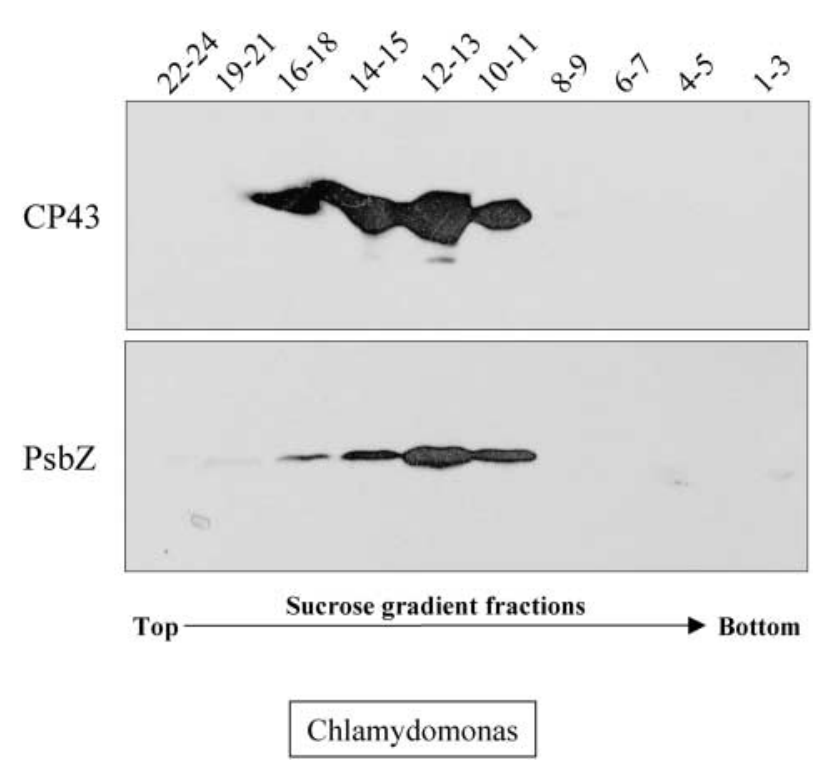

Figure 6. Cosedimentation of PsbZ and CP43 in Sucrose Gradient Fractions.

Thylakoid membranes from wild-type Chlamydomonas grown under heterotrophic conditions were solubilized with $1.25 \%$ digitonin and $1 \%$ Triton X-100 and sedimented through a 10 to $40 \%$ sucrose gradient. The 24 fractions from the gradient were pooled into 10 samples for subsequent analysis, as shown by the numbers at the top of each lane. Proteins were separated by denaturing urea (8 M)-SDS12 to $18 \%$ PAGE, transferred onto polyvinylidene difluoride membranes, and immunoblotted with antisera against CP43 and PsbZ. 
A

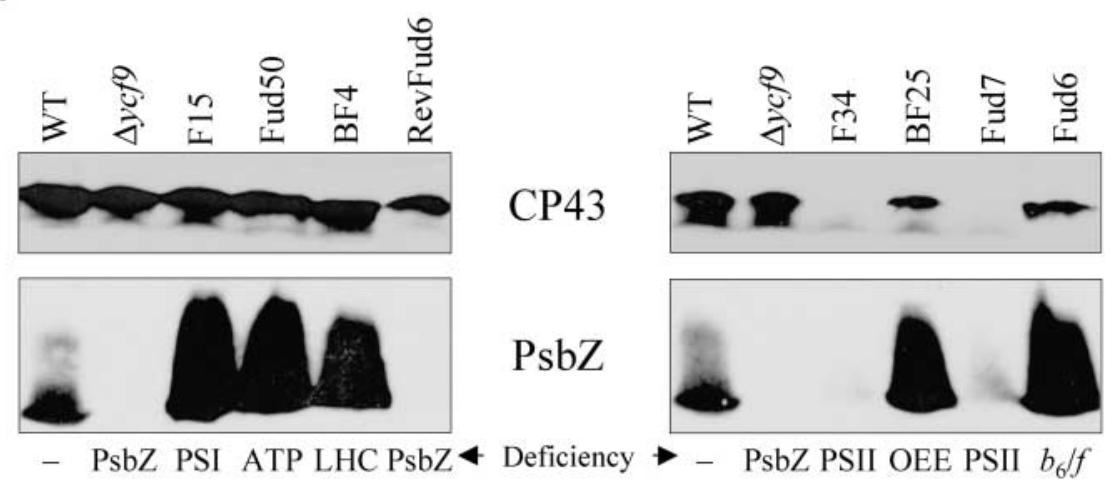

Chlamydomonas

B

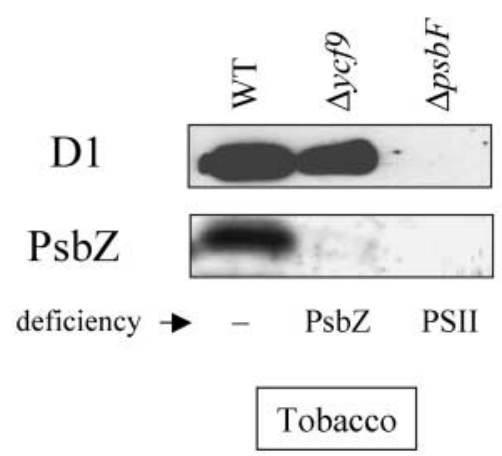

Figure 7. PsbZ Fails to Accumulate in Photosystem II Deficient Mutants.

(A) Accumulation of CP43 and PsbZ in Chlamydomonas strains deficient in the accumulation of the major protein complexes of the photosynthetic membrane. Chlamydomonas was grown under heterotrophic conditions, and thylakoid membrane proteins were separated by denaturing urea (8 M)-SDS-12 to 18\% PAGE, electroblotted onto polyvinylidene difluoride membranes, and reacted with antisera raised against PsbZ and CP43.

(B) Accumulation of D1 and PsbZ in wild-type and mutant tobacco plants. Tobacco plants were grown at $25^{\circ} \mathrm{C}$ under $100 \mu \mathrm{E} \cdot \mathrm{m}^{-2}$.sec ${ }^{-1}$. Thylakoid membrane proteins were separated by denaturing $13 \%$ SDS-tricine polyacrylamide gel electrophoresis, electroblotted onto polyvinylidene difluoride membranes, and probed with antisera raised against PsbZ and D1.

At the bottom of each lane, the major deficiency in each strain is indicated. $b_{6} / f$, cytochrome $b_{6} / f$; LHC, light-harvesting antenna complex; OEE, oxygen-evolving enhancer subunits; WT, wild type.

antenna complexes (see Figures 11B and 11D). However, it was possible that some of the minor antenna complexes might have been affected, especially given the loss of PSII supercomplexes. To assess the content of minor antenna complexes, we used specific antibodies. Figure 10A shows that in tobacco, the contents of the minor antenna proteins CP29 and CP26 depended on growth conditions. In agreement with the report from Ruf et al. (2000), we found that under most growth conditions, less CP26 accumulated in the $\Delta y c f 9$ mutant relative to that of the wild-type control. The deficiency in CP26 was most pronounced at $20^{\circ} \mathrm{C}$ in dim light, conditions under which the plants exhibited a dwarf phenotype. In most cases, CP29 content did not vary, with the notable exception of dwarf $\Delta y c f 9$ plants, in which CP29 decreased by $\sim 50 \%$. In contrast, both PsbS, an antenna-like associated PSII subunit, and CP24 were present in a constant amount in both mutant and wild-type plants. Because CP43, a major PSII core antenna subunit, showed no differences between wild-type and $\Delta y c f 9$ plants in each 
growth condition (Figure 10A), we conclude that the absence of PsbZ had a selective effect on the accumulation of minor antenna proteins that was independent of the overall accumulation of PSII cores.

Figure $10 \mathrm{~B}$ shows a similar analysis for Chlamydomonas cells grown under either heterotrophic (TAP) or photoautotrophic (minimal medium [Min]) conditions with various light and temperature regimens. On the basis of the CP43 content, we observed no differences between wild-type and $\Delta y c f 9$ strains when grown under dim light either in standard growth conditions (TAP, at $25^{\circ} \mathrm{C}$ under $10 \mu \mathrm{E} \cdot \mathrm{m}^{-2} \cdot \mathrm{sec}^{-1}$ ) or in photoautotrophic conditions (Min, at $25^{\circ} \mathrm{C}$ under $10 \mu \mathrm{E}$. $\left.\mathrm{m}^{-2} \cdot \mathrm{sec}^{-1}\right)$. When grown under photoautotrophic conditions at higher light intensities (at $25^{\circ} \mathrm{C}$ under $100 \mu \mathrm{E} \cdot \mathrm{m}^{-2} \cdot \mathrm{sec}^{-1}$ ), both wild-type and mutant cells displayed a $50 \%$ loss of CP26 as compared with cells grown under standard conditions. When the temperature was dropped to $17^{\circ} \mathrm{C}$, the wildtype cells exhibited a $40 \%$ decrease in the content of both CP26 and CP29. However, the loss was further pronounced in $\Delta y c f 9$ cells, with only $5 \%$ of CP26 and $10 \%$ of CP29 remaining under such conditions. Thus, the ycf9 deletion enhanced the light-dependent and temperature-dependent loss of two minor chlorophyll antenna proteins. It is of note that under the same conditions that affected CP29 and/or CP26, the accumulation of CP43 also decreased in $\Delta y c f 9$, but to a lesser extent (Figure 10B, top row). It is likely that the variations in relative amounts of PSIl cores and minor antenna complexes are the result of independent processes because there is overwhelming genetic evidence that PSII core subunits and minor antenna complexes generally accumulate independently in Chlamydomonas (Wollman et al., 1999).

\section{Protein Phosphorylation Alterations in Tobacco $\Delta y c f 9$}

It is well documented that the interaction between the peripheral antenna and the PSII cores is controlled by the phosphorylation of several antenna subunits in a process known as state transitions, in which a portion of LHCll detaches from PSII cores as a result of its increased phosphorylation by an activated kinase (reviewed in Allen, 1992). Thus, the loss of PSII-LHCII supercomplexes in $\Delta y c f 9$ mutants could result from changes in the phosphorylation patterns of PSII components as well as, or instead of, from a direct steric contribution of PsbZ to the interaction of the PSIl cores with their peripheral antenna. To monitor the phosphorylation status of thylakoid membranes, we used antibodies raised against phosphothreonine residues. Thylakoid membranes isolated from the tobacco mutant grown in conditions that produced a marked phenotype displayed two spectacular changes (Figure 11A): on the one hand, phosphorylation of two PSII core subunits, CP43 and D1, was decreased markedly in $\Delta y c f 9$ compared with that of the wild type in the two growth conditions we tested; on the other hand, LHCIl antenna phosphorylation was increased strongly in $\Delta y c f 9$ compared with that of the wild type when plants were grown at $25^{\circ} \mathrm{C}$ in high light, whereas the opposite effect was observed at $20^{\circ} \mathrm{C}$ under dim light. Because the overall accumulation of PSII (as monitored by D1) and LHCII was similar in wild-type and mutant leaves grown under similar conditions (Figure 11B), the differences observed in the phosphoprotein patterns were attributed to changes in the steady state phosphorylation level between PSII and LHCIl subunits: the ratio of protein phosphorylation in LHCII versus PSII was enhanced greatly in $\Delta y c f 9$ plants in the two conditions we studied. A similar approach was used with thylakoid membranes of Chlamydomonas cells grown under photoautotrophic conditions at $25^{\circ} \mathrm{C}$ in dim light or at $17^{\circ} \mathrm{C}$ in high light (Figures $11 \mathrm{C}$ and 11D). In both cases, larger amounts of phosphorylated LHCIl and smaller amounts of phosphorylated PSII (monitored by the psbH subunit) accumulated in the mutant compared with the amounts in the wild type, again suggesting that the loss of PsbZ altered the steady state level of phosphorylation between PSII and LHCII subunits.

\section{Nonphotochemical Quenching and the Xanthophyll Cycle}

To prevent photooxidative damage of the photosynthetic apparatus induced under high light, most of the photosynthetic organisms have developed nonradiative pathways that dissipate excess light energy absorbed by the antenna system. Because these dissipative pathways compete with fluorescence emission, fluorescence quenching can be recorded. Comparative measurements of the maximum level of fluorescence in dark-adapted samples $\left(F_{\max }\right)$ and after a period of high light treatment $\left(F^{\prime}{ }_{\text {max }}\right)$ allow one to calculate the nonphotochemical quenching of chlorophyll fluorescence (NPQ) as $\left(F_{\max }-F_{\text {max }}^{\prime}\right) / F_{\text {max }}^{\prime}$ (reviewed in Horton, 1996). Figure 12 shows the induction and relaxation of NPQ in tobacco plants grown under standard conditions (at $25^{\circ} \mathrm{C}$ under $\left.100 \mu \mathrm{E} \cdot \mathrm{m}^{-2} \cdot \mathrm{sec}^{-1}\right)$. During the 10-min exposure under bright light $\left(2200 \mu \mathrm{E} \cdot \mathrm{m}^{-2} \cdot \mathrm{sec}^{-1}\right)$, both wild-type and $\Delta y c f 9$ plants showed typical NPQ induction. This quenching had two kinetic components, a fast phase that was completed within the first minute of illumination and a slow phase that developed steadily during the next $9 \mathrm{~min}$. Recovery took place in darkness with a half-time of $\sim 6 \mathrm{~min}$.

The amplitude of NPQ developed upon light stress was dependent on the light and temperature conditions for growth of both wild-type and mutant plants (Table 1 and Figure 12). In the wild type, the adaptation to light and temperature stress during growth (lower temperature with constant light or higher light intensity with constant temperature) induced an increase in nonradiative energy dissipation (NPQ amplitude). In contrast, the $\Delta y c f 9$ mutant displayed opposite NPQ behavior under the same experimental conditions, namely, the extent of NPQ decreased strongly under the most adverse growth conditions (Table 1). At constant 
A

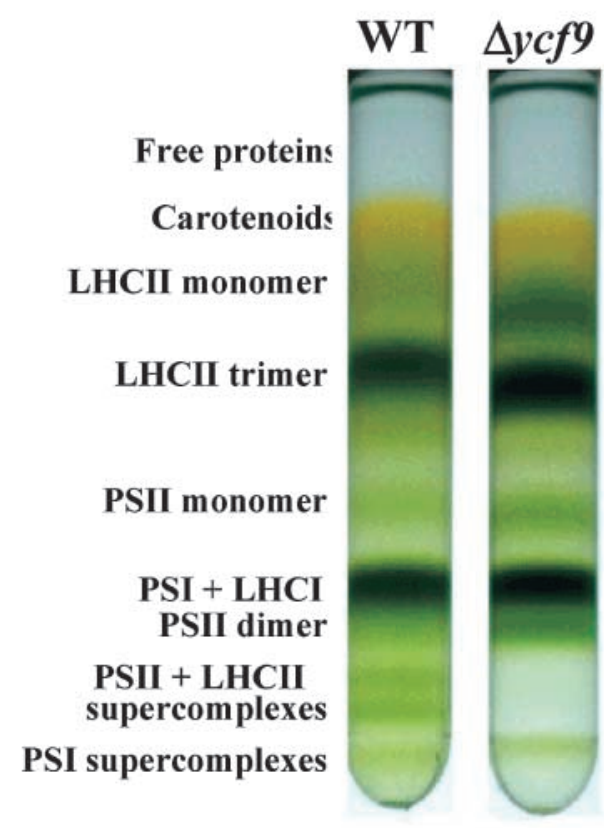

B

\section{Tobacco}
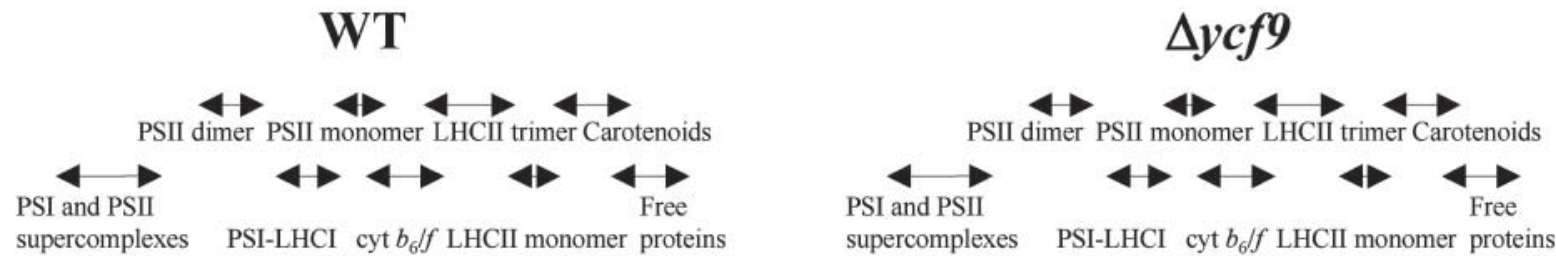

supercomplexes PSI-LHCI cyt $b_{6} / f$ LHCII monomer proteins
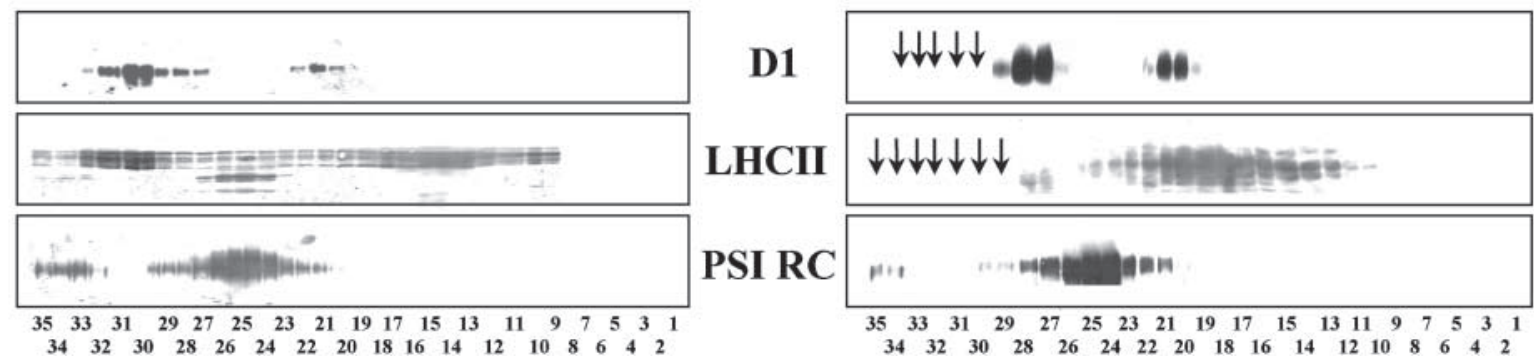

Figure 8. Chlorophyll-Protein Complexes in Wild-Type and $\Delta y c f 9$ Tobacco.

(A) Thylakoid membranes from mutant and wild-type (WT) intact chloroplasts from plants grown at $25^{\circ} \mathrm{C}$ under $100 \mu \mathrm{E} \cdot \mathrm{m}^{-2} \cdot \mathrm{sec}^{-1}$ were solubilized with dodecylmaltoside and separated in a linear 10 to $40 \%$ sucrose gradient according to Müller and Eichacker (1999). The biochemical identification of each chlorophyll-containing band, indicated at left, was assessed by collecting $0.3-\mathrm{mL}$ fractions for analysis using antisera against constituents of the major photosynthetic complexes.

(B) Immunoblot analysis of all fractions with antisera directed against D1, LHCll, and the PSI reaction center (RC). Identities of the complexes are indicated at the top of each gel and relate to the same complexes visible in (A). In the $\Delta y c f 9$ panel, vertical arrows indicate fractions in which a lack of immunoreactivity with D1 and LHCIl antibodies distinguishes these findings from results with the wild type. cyt, cytochrome. 
growth temperature, increasing the light intensity decreased the NPQ amplitude. Similarly, decreasing the temperature under constant light intensity also decreased NPQ amplitude. For $\Delta y c f 9$ plants grown under $100 \mu \mathrm{E} \cdot \mathrm{m}^{-2}$. $\mathrm{sec}^{-1}$, NPQ amplitude was $37 \%$ lower at $17^{\circ} \mathrm{C}$ than at $25^{\circ} \mathrm{C}$. Figure 12 also shows that at $17^{\circ} \mathrm{C}$, the rate of $\mathrm{NPQ}$ relaxation in the dark was affected severely in the mutant. After $10 \mathrm{~min}$ in darkness, the quenching in the wild-type leaves was reversed by $85 \%$, whereas the recovery was only $30 \%$ in $\Delta y c f 9$. Moreover, $50 \%$ of the recovery in the wild type occurred within the first 2 min of dark adaptation followed by a slow phase of recovery, whereas only the slow phase developed in the mutant. This suggests that the quenching in mutant leaves was the result of the slowly relaxing photoinhibition component rather than of the rapidly relaxing $\Delta \mathrm{pH}$-dependent component of NPQ (Horton, 1996).

Therefore, $\Delta y c f 9$ plants appear to have lost part of the adaptation mechanism that dissipates excess light energy under conditions (higher light, suboptimal growth temperature) that increase excitation pressure on PSII (Huner et al., 1998). This contrasting behavior of $\Delta y c f 9$ and wild-type plants with respect to NPQ is shown clearly in Table 1, where the ratios of NPQ amplitudes between the two genotypes are listed.

NPQ has been correlated with the activation of the xanthophyll cycle, which promotes a $\Delta \mathrm{pH}$-induced deepoxidation of violaxanthin (V) to zeaxanthin (Z) and antheraxanthin (A) (reviewed in Demmig-Adams, 1990). Table 2 shows the changes in pigment composition during a treatment aimed at inducing the xanthophyll cycle in tobacco leaves from wild-type and mutant plants. The treatment encompassed three steps: the initial state (DL) corresponded to the growth regimen at $20^{\circ} \mathrm{C}$ under $10 \mu \mathrm{E} \cdot \mathrm{m}^{-2} \cdot \mathrm{sec}^{-1}$, which was followed by an exposure to increased light intensity (900 $\left.\mu \mathrm{E} \cdot \mathrm{m}^{-2} \cdot \mathrm{sec}^{-1}\right)$ for $30 \mathrm{~min}(\mathrm{HL})$ and then by a transfer to darkness at $20^{\circ} \mathrm{C}$ for $10 \mathrm{~min}(\mathrm{HL}+$ dark). The wild-type plants initially contained more than $95 \%$ violaxanthin, and exposure to excess light induced deepoxidation, as shown by the formation of zeaxanthin. This pigment modification corresponded to a deepoxidation state (DS) of 0.33 , with $\mathrm{DS}=(\mathrm{Z}+0.5 \mathrm{~A}) /(\mathrm{Z}+\mathrm{V}+\mathrm{A})$ (Demmig-Adams and Adams, 1992). After recovery in darkness for $10 \mathrm{~min}$, the deepoxidized forms of xanthophylls decreased to $\sim 20 \%$ of total, with a DS of 0.14 .

In marked contrast to the wild-type plants, $\Delta y c f 9$ plants showed a deeply altered xanthophyll cycle. Exposure of plants to high light caused a strong increase of the deepoxidation state, with only $25 \%$ of pigments from the xanthophyll cycle remaining as violaxanthin under such conditions. Significant amounts of deepoxidized forms, including both zeaxanthin and antheraxanthin, accumulated concomitant with the disappearance of violaxanthin (DS $=0.63$ ). After a $10-\mathrm{min}$ recovery in the dark, the reepoxidation was much slower than in the wild type, and the mutant leaves still contained a large excess
A

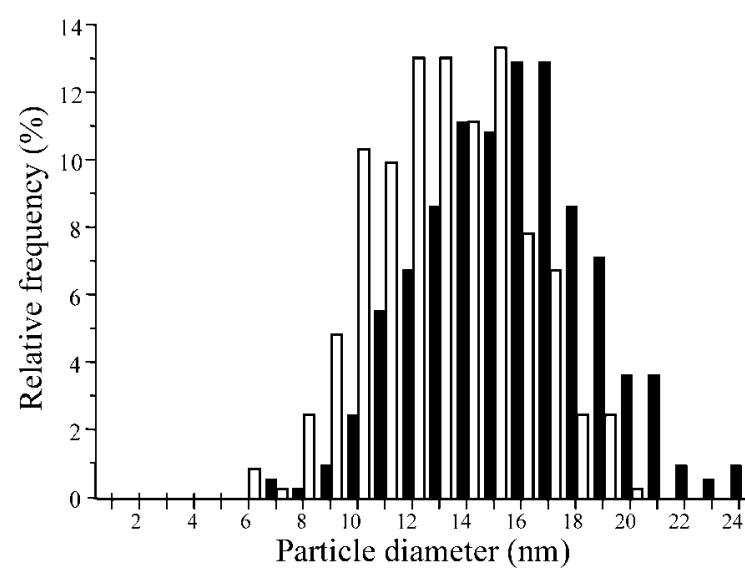

Tobacco

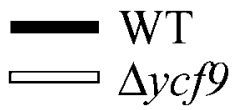

B

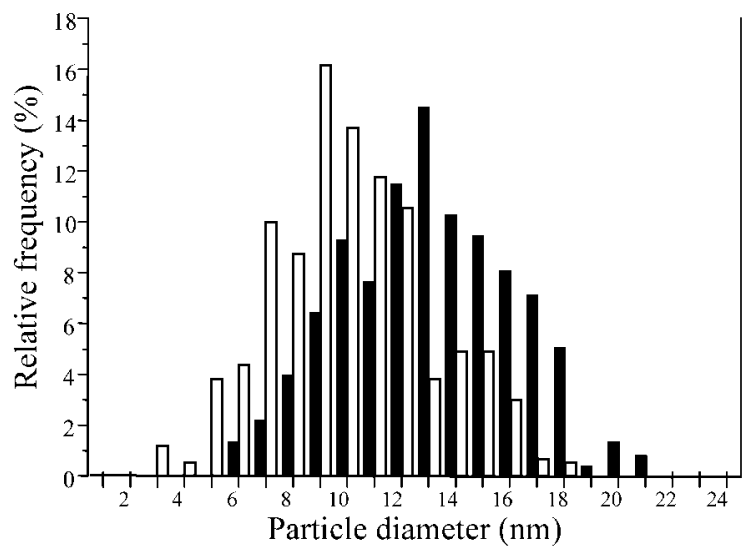

Chlamydomonas

Figure 9. Size Distribution of EF Particles in Freeze-Fractured Thylakoids.

(A) Tobacco was grown on Murashige and Skoog (1962) medium containing $20 \mathrm{~g} / \mathrm{L}$ sucrose at $25^{\circ} \mathrm{C}$ under $100 \mu \mathrm{E} \cdot \mathrm{m}^{-2} \cdot \mathrm{sec}^{-1}$.

(B) Chlamydomonas was grown on TAP medium at $25^{\circ} \mathrm{C}$ under 100 $\mu \mathrm{E} \cdot \mathrm{m}^{-2} \cdot \mathrm{sec}^{-1}$.

WT, wild type. 
A

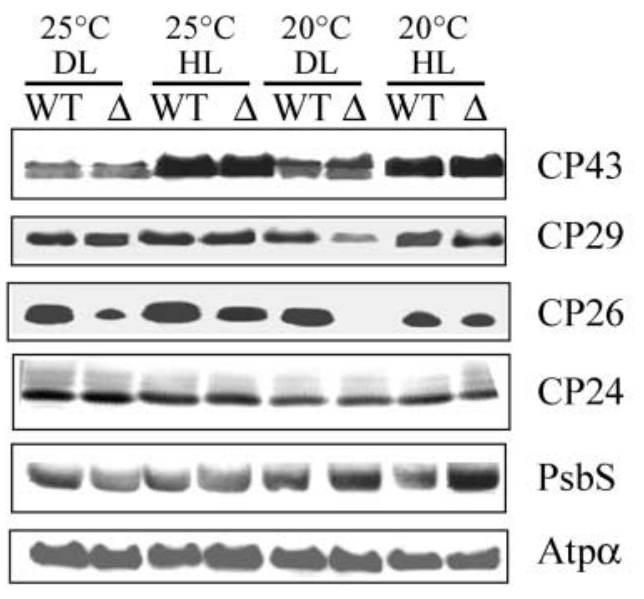

Tobacco

B

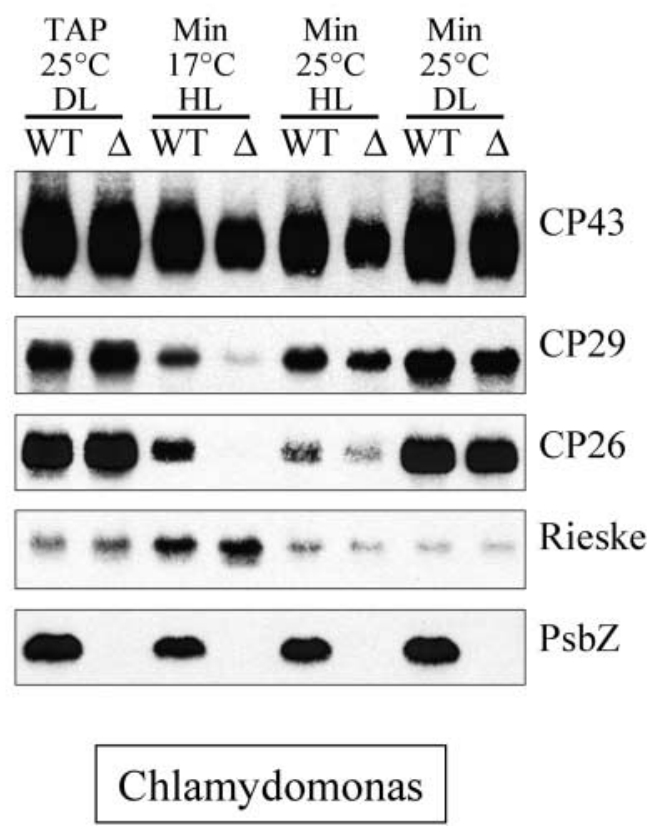

Figure 10. Effects of Growth Conditions on the Minor Antenna Contents in Thylakoid Membranes from Wild-Type and $\Delta y c f 9$.

(A) Tobacco.

(B) Chlamydomonas. TAP indicates heterotrophic growth, whereas Min indicates photoautotrophic growth in minimal medium.

Polypeptides were separated by SDS-tricine-PAGE, electroblotted onto nitrocellulose, and reacted with the specific antisera indicated at the right of each panel. DL, $10 \mu \mathrm{E} \cdot \mathrm{m}^{-2} \cdot \mathrm{sec}^{-1} ; \mathrm{HL}, 100 \mu \mathrm{E} \cdot \mathrm{m}^{-2}$. $\mathrm{sec}^{-1}$; WT, wild type; $\Delta, \Delta y c f 9$.
(65\%) of deepoxidized xanthophylls, corresponding to a DS of 0.56 .

An additional difference between wild-type and $\Delta y c f 9$ plants was the greater amount of total carotenoids present in the mutant leaves. At $10 \mu \mathrm{E} \cdot \mathrm{m}^{-2} \cdot \mathrm{sec}^{-1}$, mutant plants contained $16 \%$ more carotenoids than did the wild type on a per chlorophyll basis. After 30 min of illumination under high light, wild-type plants did not show any significant increase in carotenoid content, whereas $\Delta y c f 9$ plants exhibited a dramatic $48 \%$ increase. Interestingly, the newly synthesized carotenoids belonged to the xanthophyll cycle pool, whereas the content of other carotenoids, such as lutein, neoxanthin, and $\beta$-carotene, remained constant. Independent measurements of bleaching in high light excluded the possibility that this effect was due to photodestruction of chlorophyll rather than to xanthophyll biosynthesis (data not shown). The increase in carotenoid content was not reversible, even in part, during the subsequent incubation for $10 \mathrm{~min}$ in the dark. Thus, stress conditions specifically increased the xanthophyll complement available for deepoxidation in the mutant plants.

\section{DISCUSSION}

PSII is a major part of the photosynthetic apparatus in organisms that perform oxygenic photosynthesis. PSIl units were first defined as functional entities characterized by a large number of chlorophylls sensitizing a photochemical reaction that ultimately led to oxygen evolution and reduction of an electron acceptor whose redox state controlled the fluorescence yield of the photosynthetic apparatus. Since those early days, PSII has been broken down, conceptually as well as biochemically, into PSII reaction centers, PSII core complexes (CCII), which group the core antenna proteins CP47 and CP43 with the reaction centers, and several antenna complexes, whose association corresponds to the functional PSII unit. Although PSII reaction centers and CCII have been purified, the function of each subunit in the formation of the PSII unit remains poorly understood.

In the past decade, several small PSII subunits have been identified, most often by means of reverse genetics. Although functions have been tentatively attributed to them, their physiological importance remains elusive (reviewed in Wollman et al., 1999). Here, we demonstrate both biochemically and genetically that PsbZ, the latecomer product of the chloroplast gene ycf9, is a bona fide CCII subunit: it accumulates only in the presence of the other CCII subunits, and it copurifies on sucrose gradients with $\mathrm{CCll}$ after thylakoid membranes are solubilized with detergents. Nonetheless, we observed that PsbZ is dispensable for photoautotrophic growth and CCII assembly. However, it plays a key role in the interaction between CCII and the peripheral antenna complement. When growth conditions were chosen in such a way that limited biochemical defects were observed in the 
thylakoid membranes of a PsbZ-minus mutant (heterotrophic growth at $25^{\circ} \mathrm{C}$ ), the stability of PSII supercomplexes, which results from a tight interaction between CCII and peripheral antennae complexes, was decreased severely; these supercomplexes no longer resisted freeze fracturing or detergent solubilization of thylakoid membranes. Moreover, under more adverse growth conditions (photoautotrophic conditions for Chlamydomonas or 17 to $20^{\circ} \mathrm{C}$ for tobacco), the content of minor antenna complexes, which consist primarily of CP26 but also to some extent of CP29, decreased in the absence of PsbZ. These observations suggest that PsbZ is a key CCll subunit in the interaction with the peripheral antenna complexes.

Our study of protein phosphorylation in tobacco and Chlamydomonas thylakoids provides some decisive insight into the mechanism that allows PsbZ to play such a role. We observed that $\Delta y c f 9$ mutants displayed a marked decrease in steady state CCII phosphorylation relative to that of LHCII, as revealed by anti-phosphothreonine antibodies. Because an increased phosphorylation of LHCIl versus CCII under state II conditions leads to a detachment of some LHCIl from PSII (Allen, 1992), it is not surprising that the lower stability of PSII supercomplexes was accompanied, and very likely provoked, by the relative increase of LHCII versus CCII phosphorylation in the absence of PsbZ. Our results further suggest that the CP26 content of PSII is controlled by the distribution of phosphate groups among the phosphorylatable polypeptides that interact in the PSII units. Biochemical analysis of PSII subcomplexes has led to the proposal that CP26 interacts with CP43 and LHCII (Harrer et al., 1998), both of which are subject to phosphorylation changes. Thus, CP26 accumulation in PSII units may require the presence of its interacting partners from the PSII cores in a phosphorylated state, which is very low at $20^{\circ} \mathrm{C}$ under dim light when CP26 is not present in the mutant membranes. This putative function of PSII core subunit phosphorylation as a prerequisite for the stable assembly of the PSII unit (CCII plus chlorophyll $a / b$ binding proteins) has been proposed previously (de Vitry et al., 1989). It is supported by the observation that a Chlamydomonas mutant, BF4, that is completely devoid of the chlorophyll $a / b-c o n-$ taining complexes LHCII and CP26/CP29/CP24 does not display any PSII core phosphorylation (de Vitry and Wollman, 1988).

The critical role of PsbZ in the control of D1, CP43, and LHCIl phosphorylation can be better understood in light of the most recent studies of PSII supramolecular organization. These studies relied on mild detergent solubilization procedures and refined electron microscopy analysis, including single particle averaging (Boekema et al., 1999), cryoelectron microscopy (Nield et al., 2000), and two-dimensional crystal electron diffraction (Rhee et al., 1998; Barber and Kuhlbrandt, 1999; Hankamer et al., 1999). Various PSII forms were observed, ranging from a large protein complex retaining its peripheral antenna complement to subcore particles. In addition, a three-dimensional structure from a cyanobacterial PSII core preparation has revealed the positions of the major PSII TM helices (Zouni et al., 2001). These parallel studies highlight several structural features that cannot be assigned at present to well-identified PSII subunits. Particularly relevant to our study is the structural domain in a PSII monomer in which D1 stands in close contact to CP43, which is associated in turn with CP26 (Nield et al., 2000). Adjacent to D1 and CP43 are several TM helices of unknown origin (Zouni et al., 2001). PsbZ stands as a prominent candidate for providing some of the TM helices that are in close contact with D1, CP43, and CP26. Whether PsbZ would contribute two helices or only one TM helix to the PSII core structure remains to be determined.

Sequence analysis of PsbZ from various sources suggests a putative cleavage site for a lumenal peptidase immediately after the first of the two TM helices. The high variability in the electrophoretic migration properties of PsbZ from Chlamydomonas and tobacco with the gel systems we used precludes a definite assignment of the molecular weight of the mature product. The PsbZ-dependent interaction of PSII cores with the peripheral antenna has significant consequences for the ability of PSII to regulate the flux of light excitation. The targeted inactivation of the ycf 9 gene for PsbZ not only led to an increased lability of the minor antenna proteins, primarily CP26, but also impaired the mechanisms for excitation energy regulation in PSII, namely, the NPQ and the xanthophyll cycle. NPQ protects PSII from photoinhibition by dissipating excess excitation energy as heat. The molecular mechanism of NPQ is not fully understood. However, its full expression involves deepoxidation of violaxanthin to zeaxanthin, as shown by the marked decrease in NPQ observed in Arabidopsis mutants blocked in violaxanthin deepoxidation (Niyogi et al., 1998). It also requires the interaction of xanthophylls with LHCII proteins, as shown by the marked decrease in NPQ in the barley chlorina f2 mutant, which lacks chlorophyll $b$ and LHCII proteins (Tardy and Havaux, 1997).

As mentioned above, the major violaxanthin binding proteins, CP26 and CP29, are located at the interface between the PSII core and trimeric LHCII, which is located at the periphery of PSII supramolecular complexes (Harrer et al., 1998; Boekema et al., 1999). These minor antenna protein complexes carry protonatable residues that have been proposed to act in the sensing of low lumenal $\mathrm{pH}$, thus triggering NPQ (Walters et al., 1994, 1996; Pesaresi et al., 1997; Ruban et al., 1998). Depletion of CP26 might explain the paradoxical behavior of ycf9 mutants: although both CP29 and CP26 are able to exchange violaxanthin for zeaxanthin, this process is much more rapid for CP26 than for CP29 (Ruban et al., 1994; Croce et al., 1996). At suboptimal temperatures $\left(17\right.$ and $20^{\circ} \mathrm{C}$ ), the step of violaxanthin-to-zeaxanthin exchange might be inhibited in $\Delta y c f 9$ mutants lacking CP26 and showing some decrease in CP29, whereas at higher temperatures, this process may still occur with CP29 and in the remaining fraction of CP26, leading to the recovery of NPQ at $25^{\circ} \mathrm{C}$. The increased amplitude of the quenching 
A

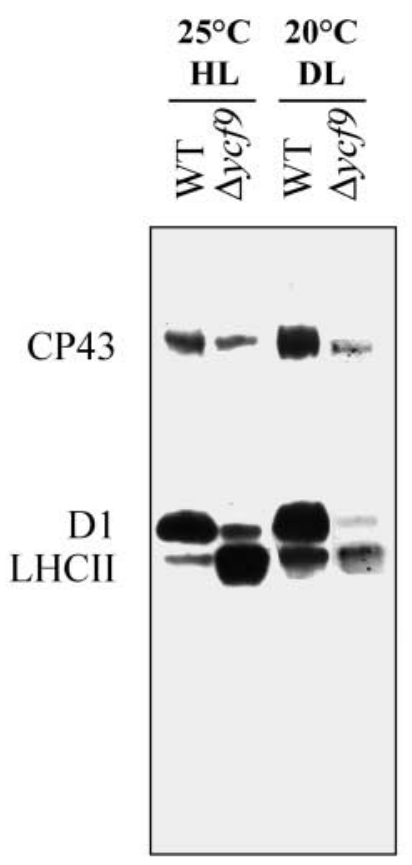

Anti-phosphothreonine

\section{Tobacco}

C

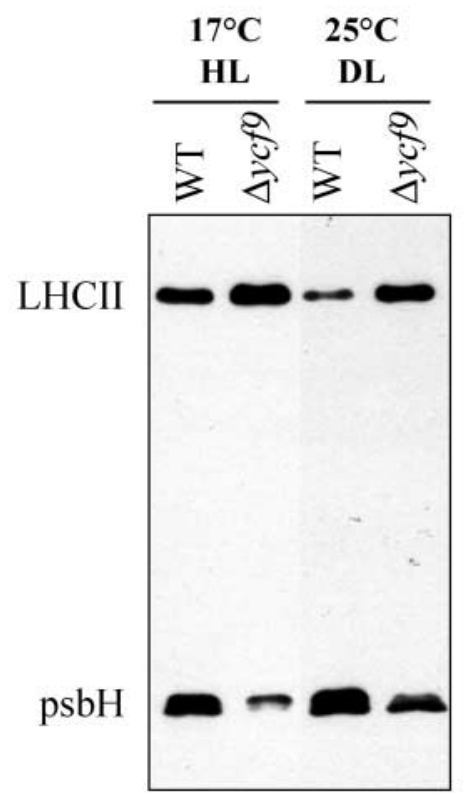

B
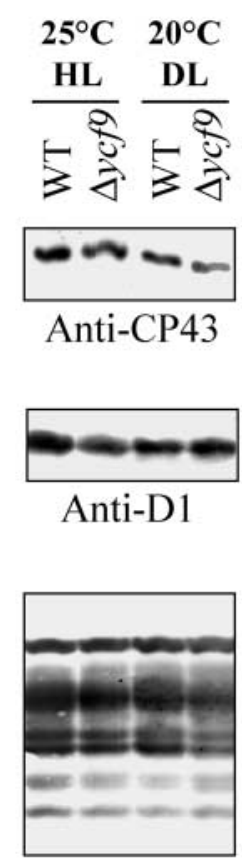

Anti-LHCII

Anti-phosphothreonine

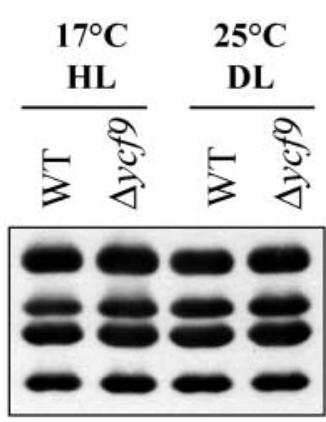

Anti-LHCII

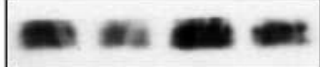

Anti-psbH

\section{Chlamydomonas}

Figure 11. Phosphorylation of Thylakoid Membrane Proteins in the Wild Type and $\Delta y c f 9$ Mutants. 
$25^{\circ} \mathrm{C}, 100 \mu \mathrm{E} \cdot \mathrm{m}^{-2} \cdot \mathrm{sec}^{-1}$

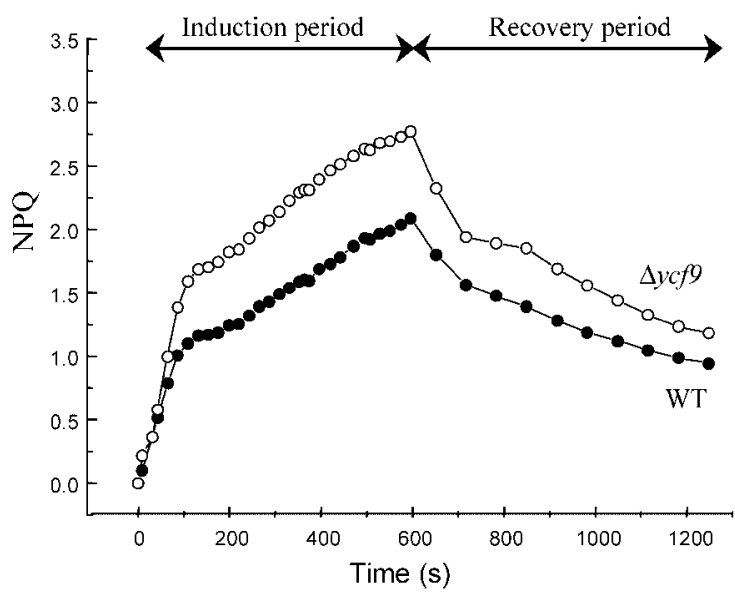

$17^{\circ} \mathrm{C}, 100 \mu \mathrm{E} \cdot \mathrm{m}^{-2} \cdot \mathrm{sec}^{-1}$

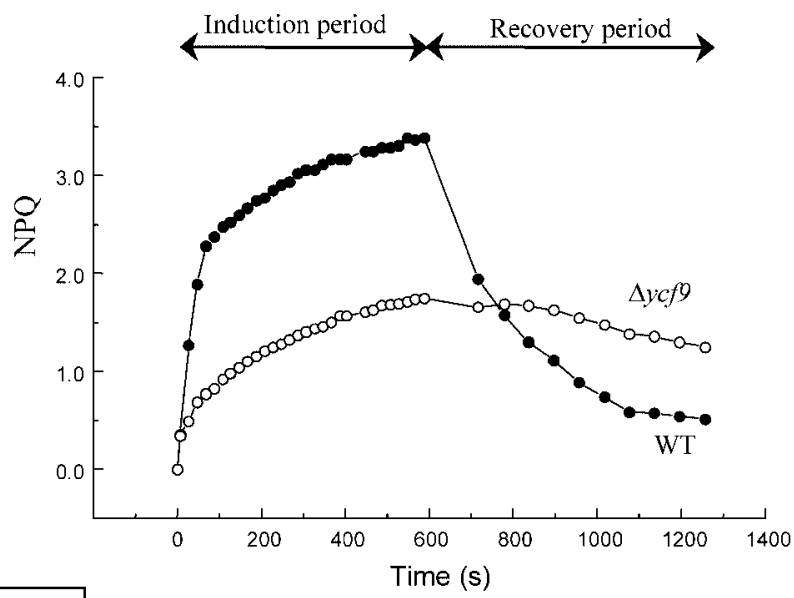

\section{Tobacco}

Figure 12. Nonphotochemical Quenching in Intact Leaves of Wild-Type and $\Delta y c f 9$ Tobacco.

Plants were grown on Murashige and Skoog (1962) medium containing $20 \mathrm{~g} / \mathrm{L}$ sucrose at $25^{\circ} \mathrm{C}$ under $100 \mu \mathrm{E} \cdot \mathrm{m}^{-2} \cdot \mathrm{sec}^{-1}$ (left) or $17^{\circ} \mathrm{C}$ (right). Nonphotochemical quenching was induced with $2200 \mu \mathrm{E} \cdot \mathrm{m}^{-2} \cdot \mathrm{sec}^{-1}$ continuous light for $10 \mathrm{~min}$, and the recovery took place in darkness. Wild type (WT), closed circles; $\Delta y c f 9$, open circles.

may be the result of the much greater content of pigments from the xanthophyll cycle in the mutant and to the higher zeaxanthin-to-violaxanthin ratio induced by strong illumination (Tables 1 and 2).

The low capacity of excitation energy dissipation also might be the reason for the dramatic increase in the carotenoid content of mutant plants with respect to wild-type plants when exposed to high light. A similar effect has been described in Chlorella vulgaris in response to high light treatment, which increases the excitation energy pressure on PSII (Maxwell et al., 1995). This also is consistent with the dwarf phenotype of $\Delta y c f 9$ plants grown at low temperature, which closely parallels the effect of PSIl overexcitation induced by moderate illumination at low temperature in bar- ley (Huner et al., 1998). We conclude that ycf9 inactivation disrupts PSII-LHCII architecture and functions in the regulation of chlorophyll a-excited states by destabilizing mainly the CP26 subunit but also CP29 under certain growth conditions. The decreased capacity for deexcitation leads to a bleaching phenotype and the overstimulation of xanthophyll synthesis required for both the recovery of NPQ and the scavenging of reactive oxygen species in the photosynthetic membrane (Havaux and Niyogi, 1999).

In summary, the functional analysis of $\Delta y c f 9$ tobacco plants suggests a critical role for PsbZ in NPQ, a process in which PsbS and CP29 were shown previously to be key players (Crofts and Yerkes, 1994; Pesaresi et al., 1997; Li et al., 2000). The CP29 contents in mutant plants varied in

Figure 11. (continued).

(A) and (B) From tobacco grown either at $25^{\circ} \mathrm{C}$ under $100 \mu \mathrm{E} \cdot \mathrm{m}^{-2} \cdot \mathrm{sec}^{-1}$ light (HL) or at $20^{\circ} \mathrm{C}$ under $10 \mu \mathrm{E} \cdot \mathrm{m}^{-2} \cdot \mathrm{sec}^{-1}$ light (DL).

(C) and (D) From Chlamydomonas grown under photoautotrophic conditions either at $17^{\circ} \mathrm{C}$ under $100 \mu \mathrm{E} \cdot \mathrm{m}^{-2} \cdot \mathrm{sec}^{-1}$ light $(\mathrm{HL})$ or at $25^{\circ} \mathrm{C}$ under $10 \mu \mathrm{E} \cdot \mathrm{m}^{-2} \cdot \mathrm{sec}^{-1}$ light (DL).

Thylakoid membrane proteins were separated by SDS-tricine-16.5\% PAGE, electroblotted onto nitrocellulose, and reacted with anti-phosphothreonine ([A] and [C]), CP43, D1, and LHCII antisera (B), or psbH and LHCIl antisera (D). The proteins were isolated as described in Methods, and the protein concentrations in the samples were normalized to the chlorophyll concentration.

WT, wild type. 
Table 1. Maximal Amplitude of Quenching after 10 Min of Exposure to Supersaturating Light ${ }^{\text {a }}$

\begin{tabular}{|c|c|c|c|c|c|c|}
\hline & \multicolumn{2}{|c|}{$25^{\circ} \mathrm{C}$} & \multicolumn{2}{|l|}{$20^{\circ} \mathrm{C}$} & \multicolumn{2}{|l|}{$17^{\circ} \mathrm{C}$} \\
\hline & $\mathrm{DL}$ & $\mathrm{HL}$ & $\mathrm{DL}$ & $\mathrm{HL}$ & $\mathrm{DL}$ & $\mathrm{HL}$ \\
\hline NPQWT & 2.60 & 2.10 & 2.70 & 3.10 & 3.10 & 3.40 \\
\hline$N P Q^{\Delta y c f 9}$ & 3.25 & 2.80 & 2.25 & 2.15 & 2.25 & 1.75 \\
\hline NPQWT/NPQ ${ }^{\Delta y c f 9}$ & 0.80 & 0.75 & 1.25 & 1.44 & 1.38 & 1.94 \\
\hline
\end{tabular}

${ }^{a}$ Measurements were performed at room temperature with plants grown at different light and temperature regimens. Before exposure to supersaturating light, plants were dark adapted for $10 \mathrm{~min}$. DL, 10 $\mu \mathrm{E} \cdot \mathrm{m}^{-2} \cdot \mathrm{sec}^{-1} ; \mathrm{HL}, 100 \mu \mathrm{E} \cdot \mathrm{m}^{-2} \cdot \mathrm{sec}^{-1}$; WT, wild type.

some of the growth conditions used in this study, but these variations did not correlate convincingly with the amplitude of the major NPQ changes. In addition, PsbS accumulation was unaltered in $\Delta y c f 9$ plants. It should be noted that PsbZ is present in phycobilisome-containing organisms, whether eukaryotes or prokaryotes, that contain neither PsbS nor CP29 and that do not undergo a xanthophyll cycle. Nonetheless, these organisms display NPQ under exposure to high light that is distinct from state transitions or photoinhibition (Campbell et al., 1998; El Bissati et al., 2000). It is tempting to suggest that PsbZ is the key player in the form of NPQ that remains in phycobilisome-containing photosynthetic organisms. Its interaction with CP43, which we inferred on the basis of its role in CP26 stability and CP43 phosphorylation, places PsbZ in a position in which it could interact with the cores to elicit an adaptation response to dissipate excess light excitation by a molecular mechanism that remains to be determined.

METHODS

\section{Growth Conditions}

Tobacco plants (Nicotiana tabacum cv Petit Havana) were grown axenically under standard light conditions $\left(100 \mu \mathrm{E} \cdot \mathrm{m}^{-2} \cdot \mathrm{sec}^{-1}\right)$ as well as under lower $\left(\sim 10 \mu \mathrm{E} \cdot \mathrm{m}^{-2} \cdot \mathrm{sec}^{-1}\right)$ light regimens, generally at 20 or $25^{\circ} \mathrm{C}$, on Murashige and Skoog (1962) agar containing $20 \mathrm{~g} / \mathrm{L}$ sucrose. For phenotypic comparisons, plants were grown in soil under greenhouse conditions. Chlamydomonas reinhardtii was kept under standard laboratory growth conditions on Tris-acetate-phosphate (TAP) plates under dim light $\left(10 \mu \mathrm{E} \cdot \mathrm{m}^{-2} \cdot \mathrm{sec}^{-1}\right)$ at $25^{\circ} \mathrm{C}$. For analytic purposes, Chlamydomonas was grown in liquid medium. When strict photosynthetic growth conditions were required, minimal medium (Min) lacking acetate was used instead of TAP. Several light and temperature regimens, as indicated above, were used during the course of this study.

\section{Mutagenesis and Transformations}

\section{Inactivation of the ycf9 Gene in Tobacco}

A 2425-bp BamHI-EcoRl fragment of tobacco plastid DNA containing ycf9 was excised from plasmid pTB20 (Shinozaki et al., 1986) with BamHI (nucleotide position 36,463; EMBL accession number Z00044) and EcoRI (position 38,889), ligated into vector pGEM$\mathrm{Zf}(-)$, and cloned in Escherichia coli $\mathrm{DH} 5 \alpha$. The ycf9 gene was inactivated by digestion with Munl at nucleotide position 37,609; this was followed by filling in the recessed ends with the Klenow fragment of DNA polymerase I and subsequent ligation with the blunt-ended, ter-

Table 2. HPLC Analysis of Changes in Pigment Composition Induced by High Light Exposure

\begin{tabular}{|c|c|c|c|c|c|c|}
\hline \multirow[b]{2}{*}{ Pigmentsa $^{a}$} & \multicolumn{2}{|l|}{$\mathrm{DL}^{\mathrm{b}}$} & \multicolumn{2}{|l|}{$\mathrm{HL}^{\mathrm{b}}$} & \multicolumn{2}{|c|}{$\mathrm{HL}+$ Dark $^{\mathrm{b}}$} \\
\hline & Wild Type & $\Delta y c f 9$ & Wild Type & $\Delta y c f 9$ & Wild Type & $\Delta y c f 9$ \\
\hline Neoxanthin & 7.0 & 6.1 & 6.4 & 6.0 & 6.3 & 5.9 \\
\hline Violaxanthin & 6.5 & 10.3 & 5.1 & 4.4 & 6.3 & 6.1 \\
\hline Antheraxanthin & 0.0 & 0.1 & 0.0 & 3.9 & 0.8 & 3.8 \\
\hline Zeaxanthin & 0.3 & 0.5 & 1.7 & 8.9 & 0.7 & 7.6 \\
\hline$\beta$-Carotene & 3.7 & 3.1 & 4.3 & 3.7 & 3.2 & 4.8 \\
\hline Lutein & 13.7 & 16.3 & 14.2 & 20.1 & 14.3 & 17.7 \\
\hline VAZ & 6.8 & 10.9 & 6.8 & 17.2 & 7.8 & 17.0 \\
\hline$(\mathrm{Z}+0.5 \mathrm{~A}) /(\mathrm{VAZ})$ & 0.044 & 0.050 & 0.33 & 0.63 & 0.14 & 0.56 \\
\hline Chlorophyll a & 71.2 & 73.8 & 75.2 & 67.0 & 76.6 & 74.9 \\
\hline Chlorophyll $b$ & 28.8 & 26.2 & 24.8 & 33.0 & 23.4 & 25.1 \\
\hline Total carotenoids & 31.2 & 36.4 & 31.7 & 47.0 & 31.6 & 46.1 \\
\hline
\end{tabular}

a Pigment compositions were normalized to 100 moles of total $(a+b)$ chlorophyll. VAZ, $\mathrm{V}+\mathrm{A}+\mathrm{Z}$. The ratio $(\mathrm{Z}+0.5 \mathrm{~A}) /(\mathrm{VAZ})$ refers to the de-epoxidation state as defined by Demmig-Adams and Adams (1992).

b Pigment compositions were measured in leaves of tobacco plants grown at $20^{\circ} \mathrm{C}$ under $10 \mu \mathrm{E} \cdot \mathrm{m}^{-2} \cdot \mathrm{sec}^{-1}$ (DL), exposed to high light (HL, 900 $\left.\mu \mathrm{E} \cdot \mathrm{m}^{-2} \cdot \mathrm{sec}^{-1}\right)$ for $30 \mathrm{~min}$, and allowed to recover in darkness for $10 \mathrm{~min}(\mathrm{HL}+$ Dark). Analyses were performed by HPLC of $80 \%$ acetone leaf extracts. 
minatorless aadA cassette (Koop et al., 1996). An individual clone carrying the aad $A$ cassette in the same polarity as $y c f 9$ (Figure 3 ) was used for transformation. Chloroplast transformation and assessment of the homoplastomic status of transformants essentially followed the procedures described by De Santis-Maciossek et al. (1999). Because the mutant genomes segregated slowly, a clonal propagation step was included to enhance plastome segregation by using a rapid and efficient system for the regeneration of plants from protoplasts with shoot formation within 2 weeks (Dovzhenko et al., 1998). The ycf9 construct containing the aadA cassette was introduced into tobacco plastid DNA by polyethylene glycol-based transformation of protoplasts (Koop et al., 1996) as well as by particle bombardment of tobacco leaves (Svab and Maliga, 1993). Both strategies yielded essentially the same results. In the former case, protoplasts were regenerated initially to small colonies of $\sim 20$ cells before selective pressure was exerted with spectinomycin to select for resistant colonies (De Santis-Maciossek et al., 1999). In the latter case, leaves were dissected $48 \mathrm{hr}$ after particle bombardment into $3 \times 3-\mathrm{mm}$ segments that were kept under nonselective conditions for 3 days and then under selective conditions. Transformation frequencies were on the order of 60 independent lines per 10 treated protoplasts or 10 treated leaves. For molecular analysis, individual transformed lines were subjected to two or three cycles of shoot regeneration. Four independent homoplastomic chloroplast transformant lines were selected and analyzed in detail.

\section{Deletion of the ycf9 Gene in Chlamydomonas}

The $\Delta y c f 9$ mutant plasmid was constructed from plasmid pCrcBX5.4 (Higgs et al., 1998) containing the 5.4-kb BamHI-Xhol fragment of the ycf9-psbM region inserted into pBluescript II KS+. pCrcBX5.4 was first digested with Pstl and then blunt ended with the T4 DNA polymerase. This linear DNA was digested with Bglll to remove the 1.1-kb fragment containing the $y c f 9$ open reading frame and then blunt ended with the Klenow fragment. The 1.9-kb EcoRV-Smal aadA cassette from atpX-aadA (Goldschmidt-Clermont, 1991) was inserted into this Pstl-Bglll-digested DNA to replace the 1.1-kb ycf9 open reading frame fragment such that aad $A$ was transcribed in the opposite orientation to $y c f 9-p s b M$.

The DuPont biolistic particle delivery system was used to transform wild-type (P17) (Stern et al., 1991) chloroplasts with $2 \mu \mathrm{g}$ of $\Delta y c f 9$ plasmid DNA, as described previously (Kindle et al., 1991). As a control, $\mathrm{P} 17$ chloroplasts also were transformed with a petD-aadA plasmid with the aadA cassette inserted in the neutral Hindlll site downstream of petD/trnR (Sakamoto et al., 1993). Potential nonphotosynthetic transformants were selected initially on TAP medium containing spectinomycin $(160 \mu \mathrm{g} / \mathrm{mL})$ in $\operatorname{dim}$ light $\left(\sim 1 \mu \mathrm{E} \cdot \mathrm{m}^{-2}\right.$. $\mathrm{sec}^{-1}$ ). Cultures were subcloned on TAP medium plus spectinomycin $(800 \mu \mathrm{g} / \mathrm{mL})$ to obtain transformants homoplasmic for the mutant chloroplast genome.

\section{DNA and RNA Analysis of Tobacco and Chlamydomonas}

Total RNA and chloroplast DNA from tobacco were prepared according to Doyle and Doyle (1990). RNA gel blot analysis was performed as described by Sambrook et al. (1989). Gene-specific DNA fragments were amplified by polymerase chain reaction (PCR) with the Taq DNA polymerase system (Qiagen, Hilden, Germany) using the following primers: 5'-CATATAGAATCAATGGATTCAT-3' (ycf9for) and 5'-CATATTCTCTTCGGAACGAT-3' (ycf9rev). Strand-specific RNA probes were prepared by in vitro transcription of PCR-amplified products in the presence of $\alpha-{ }^{32} \mathrm{P}-$ UTP using primer pairs that contained a T7 promoter sequence. Hybridizations with double-stranded DNA prepared by random priming of PCR products or with singlestranded probes were performed overnight at $65^{\circ} \mathrm{C}$ in rapid hybridization buffer (Amersham, Braunschweig, Germany). Autoradiographs were evaluated using Fuji Bio Imaging plates type BASIII, a Fuji Bio Imaging analyzer, the BAS2000 software package (Fuji, Tokyo, Japan), and the TINA software package version 2.08 beta (Raytest, Spröckhovel, Germany).

Total RNA was isolated from Chlamydomonas liquid cultures as described previously (Drager et al., 1996). RNA was fractionated on $1.2 \%$ agarose $/ 3 \%$ formaldehyde gels and blotted (Cotton et al., 1990) onto GeneScreen membranes (DuPont) followed by UV light cross-linking (UV Stratalinker 1800; Stratagene). RNA filters were hybridized with DNA-labeled probes $\left(0.5 \times 10^{6} \mathrm{cpm} / \mathrm{mL}\right)$ according to Church and Gilbert (1984). Random-primed DNA probes were synthesized from the indicated purified DNA fragments. For pet $D$ probe synthesis, a Bglll-Pstl 0.7-kb petD fragment was isolated from pCD1234 (Sakamoto et al., 1993), which has a unique Bglll site engineered at +25 relative to the petD RNA $5^{\prime}$ end. Hybridization signals were visualized with a Phosphorlmager (Molecular Dynamics, Sunnyvale, CA).

\section{Protein Isolation, Separation, and Immunoblot Analysis}

Thylakoid membranes from Chlamydomonas were isolated as described previously (Chua and Bennoun, 1975) from cultures grown to a density of $3 \times 10^{6}$ to $5 \times 10^{6} \mathrm{cells} / \mathrm{mL}$. Fractionation of the thylakoid membrane polypeptides from Chlamydomonas using Triton $X-100 /$ digitonin solubilization followed by centrifugation on sucrose density gradient was described by Diner and Wollman (1980).

Intact chloroplasts from tobacco were isolated from wild-type and mutant plants by isopycnic Percoll gradient centrifugation (Clausmeyer et al., 1993). Thylakoids were separated from stromal proteins after osmotic shock of chloroplasts and centrifugation for 10 $\mathrm{min}$ at $5000 \mathrm{~g}$. The membranes were washed in buffer containing 10 $\mathrm{mM}$ Tricine- $\mathrm{HCl}, \mathrm{pH} 8.0,0.1 \mathrm{M}$ sucrose, and $5 \mathrm{mM} \mathrm{MgCl}_{2}$. The major thylakoid protein complexes, equivalent to $3 \times 10^{8}$ chloroplasts, were separated by ultracentrifugation from dodecylmaltoside-solubilized thylakoid lysates in linear 0.1 to $1.0 \mathrm{M}$ sucrose gradients according to Müller and Eichacker (1999). The sucrose gradients were fractionated from top to bottom into 35 fractions of $300 \mu \mathrm{L}$ each using an ISCO 640 gradient fractionator. For further analysis, individual gradient fractions were precipitated with $10 \%$ trichloroacetic acid and washed with $100 \%$ acetone.

Polypeptides were separated by SDS-Tris-glycine-PAGE (Laemmli, 1970), denaturing urea-SDS-PAGE, or SDS-tricine-PAGE (Schägger and von Jagow, 1987). Samples containing Chlamydomonas materials were solubilized at $100^{\circ} \mathrm{C}$ for $50 \mathrm{sec}$ in the presence of $1 \%$ SDS and $100 \mathrm{mM} \mathrm{DTT/Na} \mathrm{Na}_{3}$ before loading. For protein gel blot analysis, proteins were transferred onto either nitrocellulose or polyvinylidene difluoride sheets according to Towbin et al. (1979). Immunodetection was performed using the enhanced chemiluminescence system of Amersham. Antisera against Ycf9 were generated by immunizing rabbits with synthetic peptides corresponding either to the Chlamydomonas (YFATPNGWTDNKGAVFS) or tobacco (PVVFASPDGWSSNKNVVFS) lumenal region of the polypeptides. Production of serum against the tobacco Ycf9 was performed according 
to Harlow and Lane (1988). Production of serum against the Chlamydomonas Ycf9 was performed by Neosystem SA (Strasbourg, France). Thylakoid phosphoproteins were immunodetected by polyclonal anti-phosphothreonine antibodies obtained from Zymed Laboratories (San Francisco, CA).

\section{Sequence Searches and Alignments}

Amino acid sequences for predicted Ycf9 open reading frames were retrieved from the fourth iteration of a $\psi$-blast search (Altschul et al., 1997) run on the server of the National Center for Biotechnology Information (NCBI) (http://www.ncbi.nlm.nih.gov/blast/psiblast.cgi) with the default parameters. Sequence alignments were performed using the CLUSTAL X multiple sequence alignment program (Jeanmougin et al., 1998). Amino acid sequences and NCBI protein databank accession numbers are from the following references: Arabidopsis thaliana (Gl:7525030) (Sato et al., 1999); C. reinhardtii (Gl:3123110) (Higgs et al.,1998); Chlorella vulgaris (Gl:7524820) (Wakasugi et al., 1997); Cyanophora paradoxa (Gl:140315) (Evrard et al., 1990); Euglena gracilis (Gl:418362) (Hallick et al., 1993); Guillardia theta (Gl:6136643) (Douglas and Penny, 1999); Hordeum vulgare (Gl:140319) (Quigley and Weil, 1985); Marchantia polymorpha (Gl:140316) (Ohyama et al., 1986); Mesostigma viride (Gl:7259550) (Lemieux et al., 2000); Nephroselmis olivacea (Gl:5880751) (Turmel et al., 1999); N. tabacum (Gl:140318) (Shinozaki et al., 1986); Odontella sinensis (Gl:1351786) (Kowallik et al., 1995); Oenothera elata (Gl:6723731) (Hupfer et al., 2000); Oryza sativa (Gl:140317) (Hiratsuka et al., 1989); Pinus thunbergii (Gl:7524713) (Wakasugi et al., 1994); Pisum sativum (Gl:3123098) (Bookjans et al., 1986); Porphyra purpurea (Gl:1723365) (Reith and Munholland, 1995); Skeletonema costatum (Gl:4210383) (Tada et al., 1999); Spinacia oleracea (Gl:7636103) (Schmitz-Linneweber et al., 2000); Synechocystis y PCC6803 (Gl:3123107) (Kaneko et al., 1996); Triticum aestivum (Gl:12376) (Quigley and Weil, 1985); and Zea mays (Gl:3123113) (Maier et al., 1995).

\section{Nonphotochemical Quenching}

For video imaging fluorescence analysis, images were collected (25msec exposure) with a solid state charge-coupled device video camera (model 4710; Cohu, San Diego, CA) through a red filter. For determination of nonphotochemical quenching of chlorophyll fluorescence (NPQ), plants were dark adapted for $15 \mathrm{~min}$. Measurements were performed as follows. Plants were illuminated with strong actinic light $\left(2200 \mu \mathrm{E} \cdot \mathrm{m}^{-2} \cdot \mathrm{sec}^{-1}\right)$ for $10 \mathrm{~min}$ followed by 12 min of dark recovery. Actinic light was interrupted for periods of 2 sec during which the maximum fluorescence yield was recorded with an orange light-emitting diode light of $800 \mu \mathrm{E} \cdot \mathrm{m}^{-2} \cdot \mathrm{sec}^{-1}$. Images for fluorescence determination were taken $0.9 \mathrm{sec}$ after the onset of this detection light. NPQ was calculated as $\left(F_{\max }-F^{\prime}{ }_{\max }\right) / F^{\prime}{ }_{\max }$ (Li et al., 2000) where $F_{\max }$ is the maximum fluorescence in the dark-adapted state and $\mathrm{F}_{\text {max }}^{\prime}$ is the maximum fluorescence in any light-adapted state. The duration of illumination by detecting light was $1.8 \mathrm{sec}$ during the treatment with actinic light and 0.9 sec during dark recovery.

\section{Pigment Analysis}

Chlorophyll concentration was determined as described by Arnon (1949). HPLC analysis was performed according to Gilmore and Yamamoto (1991).

\section{Freeze Fracturing}

Tobacco thylakoid membranes and Chlamydomonas cells broken with a Yeda Press (Yeda Scientific Instruments, Rehovot, Israel) were prepared in the presence of $10 \mathrm{mM} \mathrm{MgCl}_{2}$ to preserve membrane stacking. They were frozen rapidly in Freon 22 (DuPont) on gold holders and stored in liquid nitrogen. Freeze fracturing, electron microscopy analysis, and computation of particle size distribution were then performed according to Olive et al. (1992).

\section{ACKNOWLEDGMENTS}

M.S., A.S., and R.G.H gratefully acknowledge the help of Dr. Rainer M. Maier and the skillful technical assistance of Gabriele Burkhard and Martina Reymers. We are greatly indebted to P. Bennoun and D. Beal for conceiving and building the fluorescence device used for $N P Q$ studies. We thank R. Regel for the use of the $\Delta p s b F$ mutant before publication, R. Delosme for stimulating discussions, and $M$. Guergova-Kuras for critical reading of the manuscript. Support from the following agencies and grants is acknowledged: the Centre National de la Recherche Scientifique (Unité Propre de Recherche 1261) to R.K. and F.-A.W., National Science Foundation-Centre National de la Recherche Scientifique joint contract NSF-INT 9603351 to D.B.S. and F.-A.W., National Science Foundation Grants MCB9723274 and INT-9603351 to D.B.S. and D.H., the German Research Foundation (SFB 184) and the Fonds der Chemischen Industrie to R.G.H., the German Research Foundation (SFB TR 1) to A.S., and the Ministero dell'Università e della Ricerca Scientifica Co-Finanziamento 2000 to R.B.

Received January 2, 2001; accepted April 20, 2001.

\section{REFERENCES}

Allen, J.F. (1992). Protein phosphorylation in regulation of photosynthesis. Biochim. Biophys. Acta 1098, 275-335.

Altschul, S.F., Madden, T.L., Schaffer, A.A., Zhang, J., Zhang, Z., Miller, W., and Lipman, D.J. (1997). Gapped BLAST and PSIBLAST: A new generation of protein database search programs. Nucleic Acids Res. 25, 3389-3402.

Armond, P.A., Staehelin, L.A., and Arntzen, C.J. (1977). Spatial relationship of PSI, PSII and LHC in chloroplast membranes. J. Cell Biol. 73, 400-418.

Arnon, D.I. (1949). Copper enzymes in isolated chloroplasts and polyphenol oxidase in Beta vulgaris. Plant Physiol. 24, 1-15.

Barber, J., and Kuhlbrandt, W. (1999). Photosystem II. Curr. Opin. Struct. Biol. 9, 469-475.

Boekema, E.J., Van Roon, H., Van Breemen, J.F., and Dekker, J.P. (1999). Supramolecular organization of photosystem II and its light-harvesting antenna in partially solubilized photosystem II membranes. Eur. J. Biochem. 266, 444-452.

Bookjans, G.B., Stummann, B.M., Rasmussen, O.F., and Henningsen, K.W. (1986). Structure of a 3.2-kb region of pea 
chloroplast DNA containing the gene for the 44-kD photosystem II polypeptide. Plant Mol. Biol. 6, 359-366.

Campbell, D., Hurry, V., Clarke, A.K., Gustafsson, P., and Oquist, G. (1998). Chlorophyll fluorescence analysis of cyanobacterial photosynthesis and acclimation. Microbiol. Mol. Biol. Rev. 62, 667-683.

Chua, N.H., and Bennoun, P. (1975). Thylakoid membrane polypeptides of Chlamydomonas reinhardtii: Wild-type and mutant strains deficient in photosystem II reaction center. Proc. Natl. Acad. Sci. USA 72, 2175-2179.

Church, G.M., and Gilbert, W. (1984). Genomic sequencing. Proc. Natl. Acad. Sci. USA 81, 1991-1995.

Clausmeyer, S., Klösgen, R.B., and Herrmann, R.G. (1993). Protein import into chloroplasts: The hydrophilic lumenal proteins exhibit unexpected import and sorting specificities in spite of structurally conserved transit peptides. J. Biol. Chem. 268, 1386913876.

Cotton, J.L.S., Ross, C.W., Byrne, D.H., and Colbert, J.T. (1990). Down regulation of phytochrome mRNA abundance by red light and benzyladenine in etiolated cucumber cotyledons. Plant Mol. Biol. 14, 707-714.

Croce, R., Breton, J., and Bassi, R. (1996). Conformational changes induced by phosphorylation in the CP29 subunit of photosystem II. Biochemistry 35, 11142-11148.

Crofts, A.R., and Yerkes, C.T. (1994). A molecular mechanism for $q(E)$-quenching. FEBS Lett. 352, 265-270.

Demmig-Adams, B. (1990). Carotenoids and photoprotection in plants: A role for the xanthophyll zeaxanthin. Biochim. Biophys. Acta 1020, 1-24.

Demmig-Adams, B., and Adams, W.W.I. (1992). Carotenoid composition in sun and shade leaves of plants with different life forms. Plant Cell Environ. 15, 411-419.

De Santis-Maciossek, G., Kofer, W., Bock, A., Schoch, S., Maier, R.M., Wanner, G., Rudiger, W., Koop, H.U., and Herrmann, R.G. (1999). Targeted disruption of the plastid RNA polymerase genes $r p o A, B$ and $C 1$ : Molecular biology, biochemistry and ultrastructure. Plant J. 18, 477-489.

de Vitry, C., and Wollman, F.-A. (1988). Changes in phosphorylation of thylakoid membrane proteins in light-harvesting complex mutants from Chlamydomonas reinhardtii. Biochim. Biophys. Acta 933, 444-449.

de Vitry, C., Olive, J., Drapier, D., Recouvreur, M., and Wollman, F.A. (1989). Posttranslational events leading to the assembly of photosystem II protein complex: A study using photosynthesis mutants from Chlamydomonas reinhardtii. J. Cell Biol. 109, 9911006.

Diner, B.A., and Wollman, F.A. (1980). Isolation of highly active photosystem II particles from a mutant of Chlamydomonas reinhardtii. Eur. J. Biochem. 110, 521-526.

Douglas, S.E., and Penny, S.L. (1999). The plastid genome of the cryptophyte alga, Guillardia theta: Complete sequence and conserved synteny groups confirm its common ancestry with red algae. J. Mol. Evol. 48, 236-244.

Dovzhenko, A., Bergen, U., and Koop, H.-U. (1998). Thin-alginatelayer technique for protoplast culture of tobacco leaf protoplasts: Shoot formation in less than two weeks. Protoplasma 204, 114-118.
Doyle, J.J., and Doyle, J.L. (1990). Isolation of plant DNA from fresh tissue. Focus 12, 13-15.

Drager, R.G., Zeidler, M., Simpson, C.L., and Stern, D.B. (1996). A chloroplast transcript lacking the 3 inverted repeat is degraded by 35 exoribonuclease activity. RNA 2, 652-663.

El Bissati, K., Delphin, E., Murata, N., Etienne, A., and Kirilovsky, D. (2000). Photosystem II fluorescence quenching in the cyanobacterium Synechocystis PCC 6803: Involvement of two different mechanisms. Biochim. Biophys. Acta 1457, 229-242.

Erickson, J.M., Pfister, K., Rahire, M., Togasaki, R.K., Mets, L., and Rochaix, J.D. (1989). Molecular and biophysical analysis of herbicide-resistant mutants of Chlamydomonas reinhardtii: Structure-function relationship of the photosystem II D1 polypeptide. Plant Cell 1, 361-371.

Evrard, J.L., Weil, J.H., and Kuntz, M. (1990). An ORF potentially encoding a $6.5-\mathrm{kDa}$ hydrophobic protein in chloroplasts is also present in the cyanellar genome of Cyanophora paradoxa. Plant Mol. Biol. 15, 779-781.

Gilmore, A.M., and Yamamoto, H.Y. (1991). Resolution of lutein and zeaxanthin using a nonendcapped, lightly carbon-loaded C-18 high-performance liquid chromatographic column. J. Chromatogr. 543, 137-145.

Goldschmidt-Clermont, M. (1991). Transgenic expression of aminoglycoside adenine transferase in the chloroplast: A selectable marker of site-directed transformation of Chlamydomonas. Nucleic Acids Res. 19, 4083-4089.

Hallick, R.B., Hong, L., Drager, R.G., Favreau, M.R., Monfort, A., Orsat, B., Spielmann, A., and Stutz, E. (1993). Complete sequence of Euglena gracilis chloroplast DNA. Nucleic Acids Res. 21, 3537-3544.

Hankamer, B., Morris, E.P., and Barber, J. (1999). Revealing the structure of the oxygen-evolving core dimer of photosystem II by cryoelectron crystallography. Nat. Struct. Biol. 6, 560-564.

Harlow, E., and Lane, D. (1988). Antibodies. A Laboratory Manual. (Cold Spring Harbor, NY: Cold Spring Harbor Laboratory Press).

Harrer, R., Bassi, R., Testi, M.G., and Schafer, C. (1998). Nearestneighbor analysis of a photosystem II complex from Marchantia polymorpha L. (liverwort), which contains reaction center and antenna proteins. Eur. J. Biochem. 255, 196-205.

Havaux, M., and Niyogi, K.K. (1999). The violaxanthin cycle protects plants from photooxidative damage by more than one mechanism. Proc. Natl. Acad. Sci. USA 96, 8762-8767.

Higgs, D.C., Kuras, R., Kindle, K.L., Wollman, F.A., and Stern, D.B. (1998). Inversions in the Chlamydomonas chloroplast genome suppress a petD 5 untranslated region deletion by creating functional chimeric mRNAs. Plant J. 14, 663-671.

Hiratsuka, J., et al. (1989). The complete sequence of the rice (Oryza sativa) chloroplast genome: Intermolecular recombination between distinct tRNA genes accounts for a major plastid DNA inversion during the evolution of the cereals. Mol. Gen. Genet. 217, 185-194.

Horton, P. (1996). Non-photochemical quenching of chlorophyll fluorescence. In Light as Energy Source and Information Carrier in Plant Physiology, R.C. Jennings, G. Zucchelli, F. Ghetti, and G. Colombetti, eds (London: Plenum Press), pp. 99-112.

Huner, N.P., Oquist, G., and Sarhan, F. (1998). Energy balance and acclimation to light and cold. Trends Plant Sci. 3, 224-230. 
Hupfer, H., Swiatek, M., Hornung, S., Herrmann, R.G., Maier, R.M., Chiu, W.L., and Sears, B. (2000). Complete nucleotide sequence of the Oenothera elata plastid chromosome, representing plastome I of the five distinguishable euoenothera plastomes. Mol. Gen. Genet. 263, 581-585.

Jeanmougin, F., Thompson, J.D., Gouy, M., Higgins, D.G., and Gibson, T.J. (1998). Multiple sequence alignment with Clustal X. Trends Biochem. Sci. 23, 403-405.

Kaneko, T., et al. (1996). Sequence analysis of the genome of the unicellular cyanobacterium Synechocystis sp. strain PCC6803. II. Sequence determination of the entire genome and assignment of potential protein-coding regions. DNA Res. 3, 109-136.

Kindle, K.L., Richards, K.L., and Stern, D.B. (1991). Engineering the chloroplast genome: Techniques and capabilities for chloroplast transformation in Chlamydomonas reinhardtii. Proc. Natl. Acad. Sci. USA 88, 1721-1725.

Koop, H.U., Steinmuller, K., Wagner, H., Rossler, C., Eibl, C., and Sacher, L. (1996). Integration of foreign sequences into the tobacco plastome via polyethylene glycol-mediated protoplast transformation. Planta 199, 193-201.

Kowallik, K.V., Stoebe, B., Schaffran, I., Kroth-Pancic, P., and Freier, U. (1995). The chloroplast genome of a chlorophyll a+c-containing alga, Odontella sinensis. Plant Mol. Biol. Rep. 13, 336-342.

Laemmli, U.K. (1970). Cleavage of structural proteins during the assembly of the head of bacteriophage T4. Nature 227, 680-685.

Lemieux, C., Otis, C., and Turmel, M. (2000). Ancestral chloroplast genome in Mesostigma viride reveals an early branch of green plant evolution. Nature 403, 649-652.

Li, X.P., Bjorkman, O., Shih, C., Grossman, A.R., Rosenquist, M., Jansson, S., and Niyogi, K.K. (2000). A pigment-binding protein essential for regulation of photosynthetic light harvesting. Nature 403, 391-395.

Mäenpää, P., Gonzalez, E.B., Chen, L., Khan, M.S., Gray, J.C., and Aro, E.M. (2000). The ycf 9 (orf 62) gene in the plant chloroplast genome encodes a hydrophobic protein of stromal thylakoid membranes. J. Exp. Bot. 51, 375-382.

Maier, R.M., Neckermann, K., Igloi, G.L., and Kossel, H. (1995). Complete sequence of the maize chloroplast genome: Gene content, hotspots of divergence and fine tuning of genetic information by transcript editing. J. Mol. Biol. 251, 614-628.

Majeran, W., Olive, J., Drapier, D., Vallon, O., and Wollman, F.-A. (2001). The light sensitivity of ATP synthase mutants of Chlamydomonas reinhardtii. Plant Physiol., in press.

Maxwell, D.P., Falk, S., and Huner, N.P.A. (1995). Photosystem II excitation pressure and development of resistance to photoinhibition. I. Light-harvesting complex II abundance and zeaxanthin content in Chlorella vulgaris. Plant Physiol. 107, 687-694.

Müller, B., and Eichacker, L.A. (1999). Assembly of the D1 precursor in monomeric photosystem II reaction center precomplexes precedes chlorophyll a-triggered accumulation of reaction center II in barley etioplasts. Plant Cell 11, 2365-2378.

Murashige, T., and Skoog, F. (1962). A revised medium for rapid growth and bioassays with tobacco tissue culture. Physiol. Plant. 15, 493-497.

Nield, J., Orlova, E.V., Morris, E.P., Gowen, B., van Heel, M., and Barber, J. (2000). 3D map of the plant photosystem II supercom- plex obtained by cryoelectron microscopy and single particle analysis. Nat. Struct. Biol. 7, 44-47.

Niyogi, K.K., Grossman, A.R., and Bjorkman, O. (1998). Arabidopsis mutants define a central role for the xanthophyll cycle in the regulation of photosynthetic energy conversion. Plant Cell 10, 1121-1134.

Ohyama, K., et al. (1986). Chloroplast gene organization deduced from complete sequence of liverwort Marchantia polymorpha chloroplast DNA. Nature 322, 572-574.

Olive, J., and Wollman, F.-A. (1998). Supramolecular organization of the chloroplast and of the thylakoid membranes. In The Molecular Biology of Chloroplasts and Mitochondria in Chlamydomonas, J.-D Rochaix, M. Goldschmidt-Clermont, and S. Merchant, eds (Dordrecht, The Netherlands: Kluwer Academic Publishers), pp. 233-254.

Olive, J., Recouvreur, M., Girard-Bascou, J., and Wollman, F.A. (1992). Further identification of the exoplasmic face particles on the freeze-fractured thylakoid membranes: A study using double and triple mutants from Chlamydomonas reinhardtii lacking various photosystem II subunits and the cytochrome b6/f complex. Eur. J. Cell Biol. 59, 176-186.

Pesaresi, P., Sandona, D., Giuffra, E., and Bassi, R. (1997). A single point mutation (E166Q) prevents dicyclohexylcarbodiimide binding to the photosystem II subunit CP29. FEBS Lett. 402, 151-156.

Quigley, F., and Weil, J.H. (1985). Organization and sequence of five tRNA genes and of an unidentified reading frame in the wheat chloroplast genome: Evidence for gene rearrangements during the evolution of chloroplast genomes. Curr. Genet. 9, 495-503.

Reith, M.E., and Munholland, J. (1995). Complete nucleotide sequence of the Porphyra purpurea chloroplast genome. Plant Mol. Biol. Rep. 13, 333-335.

Rhee, K.H., Morris, E.P., Barber, J., and Kuhlbrandt, W. (1998). Three-dimensional structure of the plant photosystem II reaction centre at 8-Å resolution. Nature 396, 283-286.

Rochaix, J.D., Kuchka, M., Mayfield, S., Schirmer-Rahire, M., Girard-Bascou, J., and Bennoun, P. (1989). Nuclear and chloroplast mutations affect the synthesis or stability of the chloroplast psbC gene product in Chlamydomonas reinhardtii. EMBO J. 8, 1013-1021.

Ruban, A.V., Young, A.J., Pascal, A.A., and Horton, P. (1994). The effects of illumination on the xanthophyll composition of the photosystem II light-harvesting complexes of spinach thylakoid membranes. Plant Physiol. 104, 227-234.

Ruban, A.V., Pesaresi, P., Wacker, U., Irrgang, K.D., Bassi, R., and Horton, P. (1998). The relationship between the binding of dicyclohexylcarbodiimide and quenching of chlorophyll fluorescence in the light-harvesting proteins of photosystem II. Biochemistry $\mathbf{3 7}, \mathbf{1 1 5 8 6 - 1 1 5 9 1 .}$

Ruf, S., Biehler, K., and Bock, R. (2000). A small chloroplastencoded protein as a novel architectural component of the lightharvesting antenna. J. Cell Biol. 149, 369-378.

Sakamoto, W., Kindle, K.L., and Stern, D.B. (1993). In vivo analysis of Chlamydomonas chloroplast petD gene expression using stable transformation of $\beta$-glucuronidase translational fusions. Proc. Natl. Acad. Sci. USA 90, 497-501. 
Sambrook, J., Fritsch, E.F., and Maniatis, T. (1989). Molecular Cloning: A Laboratory Manual, 2nd ed. (Cold Spring Harbor, NY: Cold Spring Harbor Laboratory Press).

Sato, S., Nakamura, Y., Kaneko, T., Asamizu, E., and Tabata, S. (1999). Complete structure of the chloroplast genome of Arabidopsis thaliana. DNA Res. 6, 283-290.

Schägger, H., and von Jagow, G. (1987). Tricine-sodium dodecyl sulfate-polyacrylamide gel electrophoresis for the separation of proteins in the range from 1 to $100 \mathrm{kDa}$. Anal. Biochem. 166, 368-379.

Schmitz-Linneweber, C., Maier, R., Alcaraz, J.P., Cottet, A., Hermann, R.G., and Mache, R. (2000). The plastid chromosome of spinach (Spinacia oleracea): Complete nucleotide sequence and gene organization. Plant Mol. Biol. 45, 307-315.

Shinozaki, K., et al. (1986). The complete nucleotide sequence of the tobacco chloroplast genome: Its gene organization and expression. EMBO J. 5, 2043-2049.

Stern, D.B., Radwanski, E.R., and Kindle, K.L. (1991). A 3'stem/ loop structure of the Chlamydomonas chloroplast atp $B$ gene regulates mRNA accumulation in vivo. Plant Cell 3, 285-297.

Sturm, N.R., Kuras, R., Buschlen, S., Sakamoto, W., Kindle, K.L., Stern, D.B., and Wollman, F.-A. (1994). The petD gene is transcribed by functionally redundant promoters in Chlamydomonas reinhardtii chloroplasts. Mol. Cell. Biol. 14, 6171-6179.

Svab, Z., and Maliga, P. (1993). High-frequency plastid transformation in tobacco by selection for a chimeric aadA gene. Proc. Natl. Acad. Sci. USA 90, 913-917.

Tada, N., Shibata, S., Otsuka, S., Namba, K., and Oyaizu, H. (1999). Comparison of gene arrangements of chloroplasts between two centric diatoms, Skeletonema costatum and Odontella sinensis. DNA Seq. 10, 343-347.

Tardy, F., and Havaux, M. (1997). Thermostability and photostability of photosystem II in leaves of the chlorina-F2 barley mutant deficient in light-harvesting chlorophyll $a / b$ protein. Plant Physiol. 113, 913-923.

Towbin, H., Staehelin, T., and Gordon, J. (1979). Electrophoretic transfer of proteins from polyacrylamide gels to nitrocellulose sheets: Procedure and some applications. Proc. Natl. Acad. Sci. USA 76, 4350-4354.

Turmel, M., Otis, C., and Lemieux, C. (1999). The complete chloroplast DNA sequence of the green alga Nephroselmis olivacea: Insights into the architecture of ancestral chloroplast genomes. Proc. Natl. Acad. Sci. USA 96, 10248-10253.

Wakasugi, T., Tsudzuki, J., Ito, S., Nakashima, K., Tsudzuki, T., and Sugiura, M. (1994). Loss of all $n d h$ genes as determined by sequencing the entire chloroplast genome of the black pine Pinus thunbergii. Proc. Natl. Acad. Sci. USA 91, 9794-9798.

Wakasugi, T., et al. (1997). Complete nucleotide sequence of the chloroplast genome from the green alga Chlorella vulgaris: The existence of genes possibly involved in chloroplast division. Proc. Natl. Acad. Sci. USA 94, 5967-5972.

Walters, R.G., Ruban, A.V., and Horton, P. (1994). Higher plant light-harvesting complexes LHClla and LHCllc are bound by dicyclohexylcarbodiimide during inhibition of energy dissipation. Eur. J. Biochem. 226, 1063-1069.

Walters, R.G., Ruban, A.V., and Horton, P. (1996). Identification of proton-active residues in a higher plant light-harvesting complex. Proc. Natl. Acad. Sci. USA 93, 14204-14209.

Wollman, F.A., Minai, L., and Nechushtai, R. (1999). The biogenesis and assembly of photosynthetic proteins in thylakoid membranes. Biochim. Biophys. Acta 1411, 21-85.

Yao, W.B., Meng, B.Y., Tanaka, M., and Sugiura, M. (1989). An additional promoter within the protein-coding region of the $p s b D$ $p s b C$ gene cluster in tobacco chloroplast DNA. Nucleic Acids Res. 17, 9583-9591.

Zerges, W., and Rochaix, J.D. (1994). The 5 leader of a chloroplast mRNA mediates the translational requirements for two nucleusencoded functions in Chlamydomonas reinhardtii. Mol. Cell. Biol. 14, 5268-5277.

Zouni, A., Witt, H.T., Kern, J., Fromme, P., Krauss, N., Saenger, W., and Orth, P. (2001). Crystal structure of photosystem II from Synechococcus elongatus at 3.8 A resolution. Nature 409, 739-743. 